\title{
N One Step Closer to Achieving What I Learned in School $y$
}

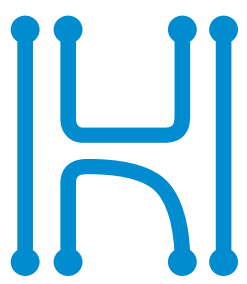

HERE TO HERE

A New Approach to Educational Equity:

How Work-Based Learning Can Address Today's Opportunity Gaps

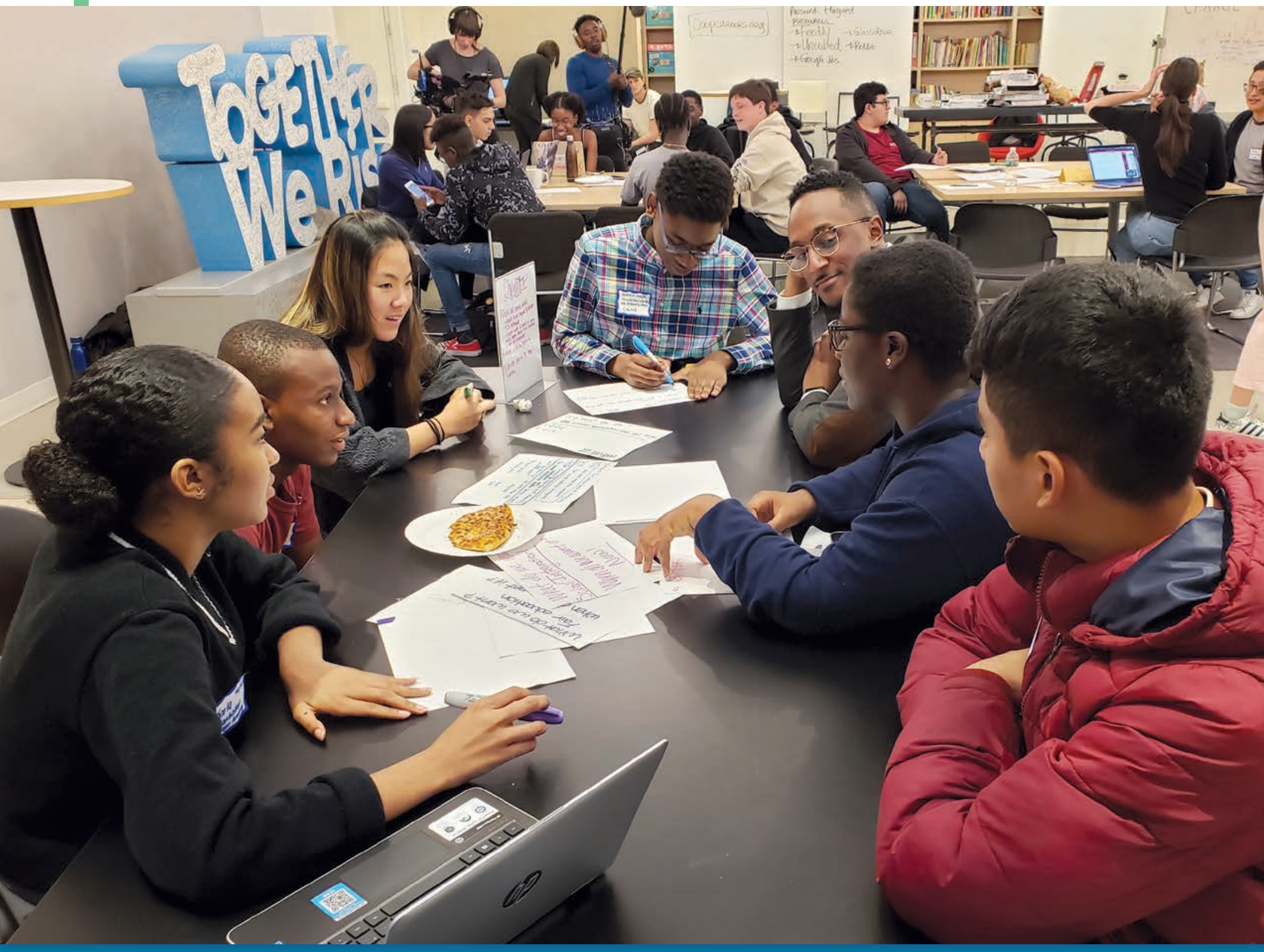

HERE TO HERE Policy Brief ｜ January 2020 


\title{
NOne Step Closer
}

\section{to Achieving What}

I Learned in School $y$

\author{
A New Approach to Educational Equity: \\ How Work-Based Learning Can Address Today's Opportunity Gaps
}

\section{HERE TO HERE Policy Brief ｜ January 2020}

Author: Lazar Treschan, Vice President, Policy and Impact

Contact: Itreschan@heretohere.org

\section{Acknowledgments}

This report was developed and written by Lazar Treschan, Vice President, Policy and Impact at HERE to HERE. Lazar joined HERE to HERE in the summer of 2019 to lead the organization's efforts to document and disseminate its demonstration projects; publish additional materials to build the case for change; and manage advocacy activities. He previously served as Director of Youth Policy at the Community Service Society of New York, and in prior policy and planning positions at New Visions for Public Schools, the NYC Department of Youth and Community Development, and Abt Associates. He has taught graduate courses in public policy at NYU, the New School, and Brooklyn College.

This report relies heavily on research conducted by Apurva Mehrotra, Director of Research and Analytics at HERE to HERE, and Coco Rhum, HERE to HERE intern and former Policy Director at Teens Take Charge - this would not have been possible without them. Numerous colleagues at HERE to HERE, including Victoria Shire, Dr. Edward Summers, Christina Samuels, Abja Midha, and Abby Jo Sigal, provided feedback, editing, design, and other assistance. Taylor McGraw also provided important feedback and thought partnership, and we are grateful to him and the student leaders at Teens Take Charge for their continued collaboration and partnership. The author is also grateful to Saskia Traill, Isa Ellis, and Saskia Levy Thompson, who provided valuable comments on drafts of this report. HERE to HERE must also acknowledge its many partners in this work, including those at the NYC Center for Youth Employment, the NYC Department of Education, CUNY, and the Department of Youth and Community Development, who have helped lead an expansion of work-based learning through CareerReadyNYC.
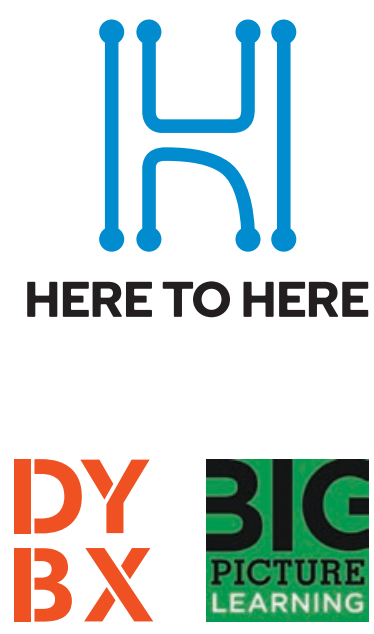

\begin{abstract}
About HERE to HERE
HERE to HERE is a Bronx-based nonprofit that unites employers, educators, and community-based organizations to connect young people to familysustaining careers and create a thriving, inclusive economy. We support people and institutions already developing career pathways and break down barriers between them.

Our goal is to build partnerships and policies that help employers identify the talent they need to thrive and ensure every student develops the passion, experience, and professional network to succeed in a career of their choice. HERE to HERE was developed by and DreamYard, Big Picture Learning, and the James and Judith K. Dimon Foundation.
\end{abstract}


I. The New Equity Gap

How segregated schools and communities are creating

vast differences in students' chances for success

II. The Work-Based Learning Equity Approach

How work-based learning can mitigate these disparities

III. The Path Forward

Our recommendations for policies and investments that will provide real equity and put more young people on the road to successful, choice-filled lives

Conclusion and Call to Action

Appendix

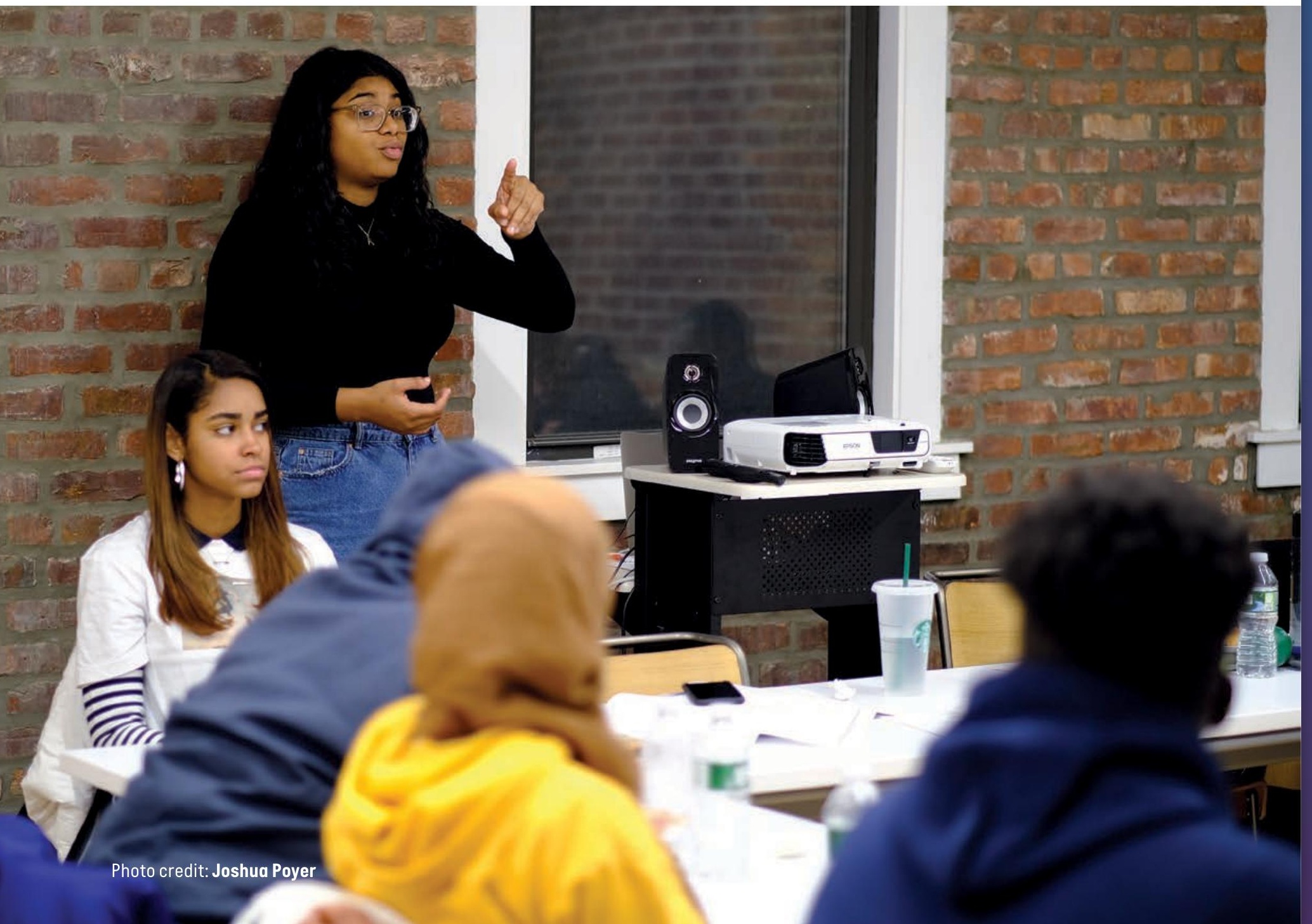




\section{Executive Summary}

Over the past 15 years, New York City has made strong progress in improving education outcomes for students, particularly related to high school graduation and college enrollment. But we still see drastic disparities for young people in the areas of college completion and employment across lines of race, ethnicity, and household income. These inequities have sharpened during recent periods of overall economic growth, highlighting how increasing inequality, gentrification, and community segregation remain persistent challenges to inclusivity and shared prosperity. This report will discuss how an expansion and enhancement of work-based learning can combat these trends.

Students in New York City's public high schools and colleges benefit from living in one of the most diverse and economically robust cities in the world, but their schools often reflect the segregation and isolation we see in many of our neighborhoods. Schools can even heighten, rather than mitigate, differences in opportunity that students already face as a result of their socioeconomic circumstances, contributing to the disparate outcomes we see in college completion and the labor market.

The desegregation of the city's public schools should be a priority in efforts to level the playing field for New York City's students. The most straightforward way to address segregation is through enrollment-focused integration efforts. As the Supreme Court ruled in 1954, the United States has never been able to offer equal services to separated racial subgroups, and today's outcomes continue to reinforce this finding, 65 years later. The authors and endorsers of this report support the ongoing efforts to diversify public schools through enrollment reforms. In addition, we believe that our public systems of education should make immediate efforts to ensure that students in under-served schools are afforded the same quality of opportunities as their peers in better-resourced schools.

We strongly believe that these opportunities must go beyond traditional academics. Before they even step in a high school building or college campus, New York City students face vast differences in the non-academic resources that play a crucial role in determining not only their career success, but also the extent to which their pathway to a career will be based on a deep knowledge of their own talents and passions, an informed understanding of the range of possible careers, and the types of education and training that are required to succeed in them. Our schools need to provide and broker experiences to young people that will bridge these gaps in opportunity, and provide all students with the foundation they need for a fulfilling life beyond high school.

HERE to HERE is very concerned about the future of our city, and its ability to address the challenges of growing inequality. In addition to integrating our schools, our public education systems need to invest in a significant expansion of work-based learning, which we believe offers the greatest potential to mitigate the opportunity gaps our students face. New York City is unique in the opportunities it can provide to students to put their learning into practice in real-world settings. Yet perhaps our two greatest educational assets, the passions and skills of many students, and the ability of employers to provide ways to explore and actualize them, go largely unrealized by education systems that overemphasize classroom instruction and assessment and far too rarely allow young people to apply their learning, explore the world of work, and most importantly, learn who they are and what they care about in that process. That needs to change.

\section{The Power of Work-Based Learning}

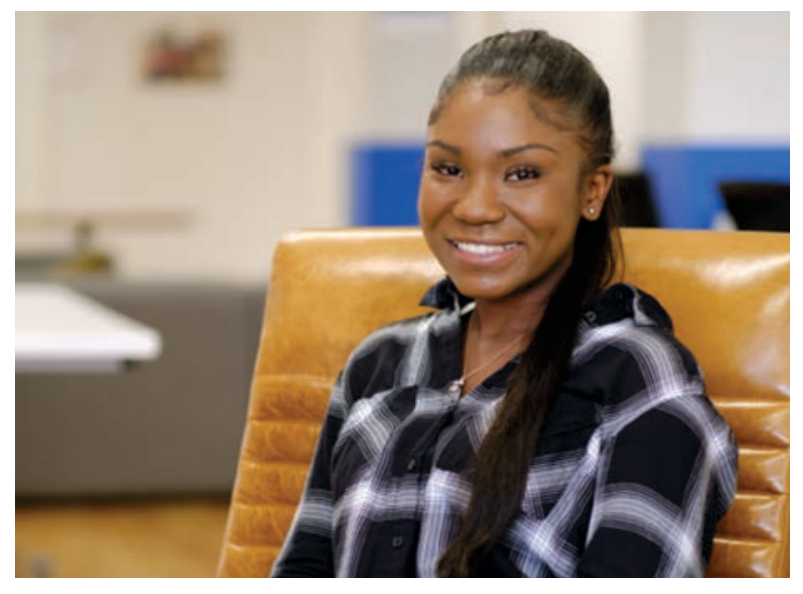

Te[From my summer job working at a summer camp for students with disabilities] I think I learned more about myself, what I'm capable of. And I learned that when something doesn't work out, I don't need to accept that I can't improve the situation at all. I'm more optimistic now. If something doesn't work out, I'll make something work out for the better.

-Crystal 
The good news is that we are not starting from scratch. There are numerous examples within New York City of $\mathrm{K}-12$ and postsecondary programs that offer students a chance to apply their classroom learning in a work-based setting, such as CTE high schools, internships, or applied degree programs at CUNY. But they remain far too limited; and private programs, which many higher income parents are able to provide to their children as vital enrichment, are out of reach for most young people.

HERE to HERE is dedicated to changing our education systems to better prepare young people for familysustaining careers and create a thriving, inclusive economy for all New Yorkers. We believe that a significant expansion and enhancement of work-based learning [WBL] represents the most promising way to do so, and a path that explicitly addresses the growing racial and socioeconomic gaps that young New Yorkers face.

HERE to HERE - along with other organizations-is already engaged in this work, by conducting several demonstration projects in high schools, postsecondary organizations, and with employers that can provide local proof points as we make the case for change. Through our policy and advocacy efforts, with a range of partners and on our own, including reports such as this one, we hope to invite others to join this movement.

\section{WHAT IS WORK-BASED LEARNING?}

Work-based learning [WBL] - a category of academic learning models embedded in the real world of work, which includes, for example, internships, apprenticeships, and other experiences that connect education to the world of work - is an approach for employers to recruit and develop talent, while also providing students with the necessary skills to enter and succeed in the workforce.'
Our findings, in brief, include:

- Students in New York City face vast differences in the opportunities available to them by nature of living in isolated communities. Labor market data tells us that low-income students, and young people of color, have social networks that include adults with a much more constricted set of educational experiences and professions, concentrated in low-income fields. White students and those from higher-income families have access to social networks with much higher shares of college graduates, and adults in a diverse set of highpaying jobs.

- Students report that their high schools heighten, rather than soften these differences in opportunities. In schools with concentrations of students from low-income households, students report having fewer opportunities to build upon their academic work with work-based learning, such as internships and other related activities. Higher-income youth report having many more chances to actualize their education through hands-on experiences, explore their interests outside of the classroom, and prepare for their next steps after graduation.

- Evidence-and students, themselves-suggest that work-based learning can address most of these gaps in opportunity caused by segregated schools and communities. Work-based learning experiences offer the chance to build social networks, gain skills and knowledge of self, and put students on a stronger pathway toward high school and postsecondary success.

"Before they even step in a high
school building or college campus,
New York City students face vast
differences in the non-academic
resources that play a crucial
role in determining not only their
career success, but also the
extent to which their pathway
to a career will be based on a
deep knowledge of their own
talents and passions, an informed
understanding of the range of
possible careers, and the types
of education and training that are
required to succeed in them."




\section{RECOMMENDATIONS, |N BRIEF}

We recommend that New York City address these equity gaps through policies and investments in work-based

learning. The final section of this report presents these in greater detail; in brief, they include:

- EMPOWERING K-12 - Providing paid internships for all high school students and dedicated staff at schools to develop internships, and connect them and other WBL activities to classroom instruction. Support the design and development of new models of WBL provision, including STEAM Centers in every borough.

Immediate next step: Pilot and learn from a WBL for All initiative in 40 high schools at a cost of $\$ 14$ million per year.

- LEVERAGING CUNY - Embedding career success initiatives across the system by reviewing incentives, expanding the resources available to support paid WBL opportunities, and evolving career services offices to where employers partner with academics to develop strong occupational pathways that braid paid work into accredited degree programs.

- Immediate next step: Support for recent CUNY budget request for new Career Engagement and Development Centers at five campuses and creation of a CUNY Internship Challenge Fund initially serving 4,000 students in year one.

- ENGAGING EMPLOYERS - Creating self-sustaining mechanisms to make employers design and implementation partners in local talent development, beginning with creation and support for intermediaries to create efficient interactions between schools and employers; identification of occupations that can serve as the foundation for how employers and educators collaborate; and vast expansion of the number and scope of workplace experiences to students in K-12 and postsecondary.

Immediate next step: Creation of designated funding streams for intermediaries for concrete, measurable engagement of employers in WBL and identification of local and state public agencies that can take the lead on these activities.

In this paper, we will present new quantitative and qualitative data that illustrate the lived experience of how segregation affects young people; why work-based learning represents a crucial way to address it; and the specific strategies we recommend to do so. We will offer labor market information that puts hard numbers on what isolation means for students who attend lowincome schools, and hear their voices about how this plays out in their lives, when their dreams and aspirations come up against the circumstances of their communities and social networks. We will also hear from students who attend schools with concentrations of higher income students, and how they are offered more opportunities to explore, develop, and actualize their academic and personal interests, with a clear focus on making a successful postsecondary transition. We will analyze how high schools, as they currently exist, serve as mechanisms that reflect and heighten those differences in opportunity, rather than actively work to mitigate them. And last, we will present an alternative model for how schools and the policymakers that govern them can take these issues into account, and transform themselves into mechanisms that target these inequities head on.

We urge the New York City Department of Education and the City University of New York [CUNY], as well as all of the City's employers, to consider the findings of this report. HERE to HERE is already committed to demonstrating the power of work-based learning through a range of demonstration projects that we are operating or supporting in high schools, postsecondary organizations, and with employers. But our success, and those of the many organizations that share our beliefs, will only be successful if the systems that govern talent development in New York City adopt these ideas and practices at scale. We hope to work with each of the systems and stakeholders to implement these recommendations. 


\section{The New Equity Gap}

When viewed broadly, New York City's public schools have seen notable improvements over the past 20 years. Test scores, high school graduation rates, and college enrollment have all risen, both in terms of citywide averages, and for most subgroups of students. ${ }^{2}$ But deeper examination shows that young people still experience a "Tale of Two Cities" in our public education systems, which, as might be expected, largely reflect the broader structural hierarchies visible across the city. We find that young people from higher-income backgrounds get many more opportunities to put what they learn in school into practice early on, giving them stronger foundations for postsecondary and career success.

Students in New York City high schools are markedly segregated along racial and economic lines. NYC schools have been described as the most segregated in the country ${ }^{3}$ and schools with higher concentrations of low-income students of color have notably different outcomes in terms of graduation, college readiness, and college attainment. ${ }^{4}$ And despite receiving less public attention, New York City's public colleges are also markedly more segregated than they were 15 years ago. ${ }^{5}$ CUNY has seen a notable stratification of students along ethnic lines in the past 12 years, with black and Latino students far more likely to enroll in community colleges, and white and Asian students occupying most of the seats in the more selective four-year campuses. ${ }^{6}$

These segregated schools lead to disparate outcomes for students. Despite improvements for all groups, high school graduation and college readiness rates remain lower for black and Latino students overall, and black and Latino students at schools where they are disproportionately concentrated have lower graduation rates compared to those at schools that are more representative of citywide racial/ethnic averages. But nearly half of black students in the class of 2018 were at segregated high schools.
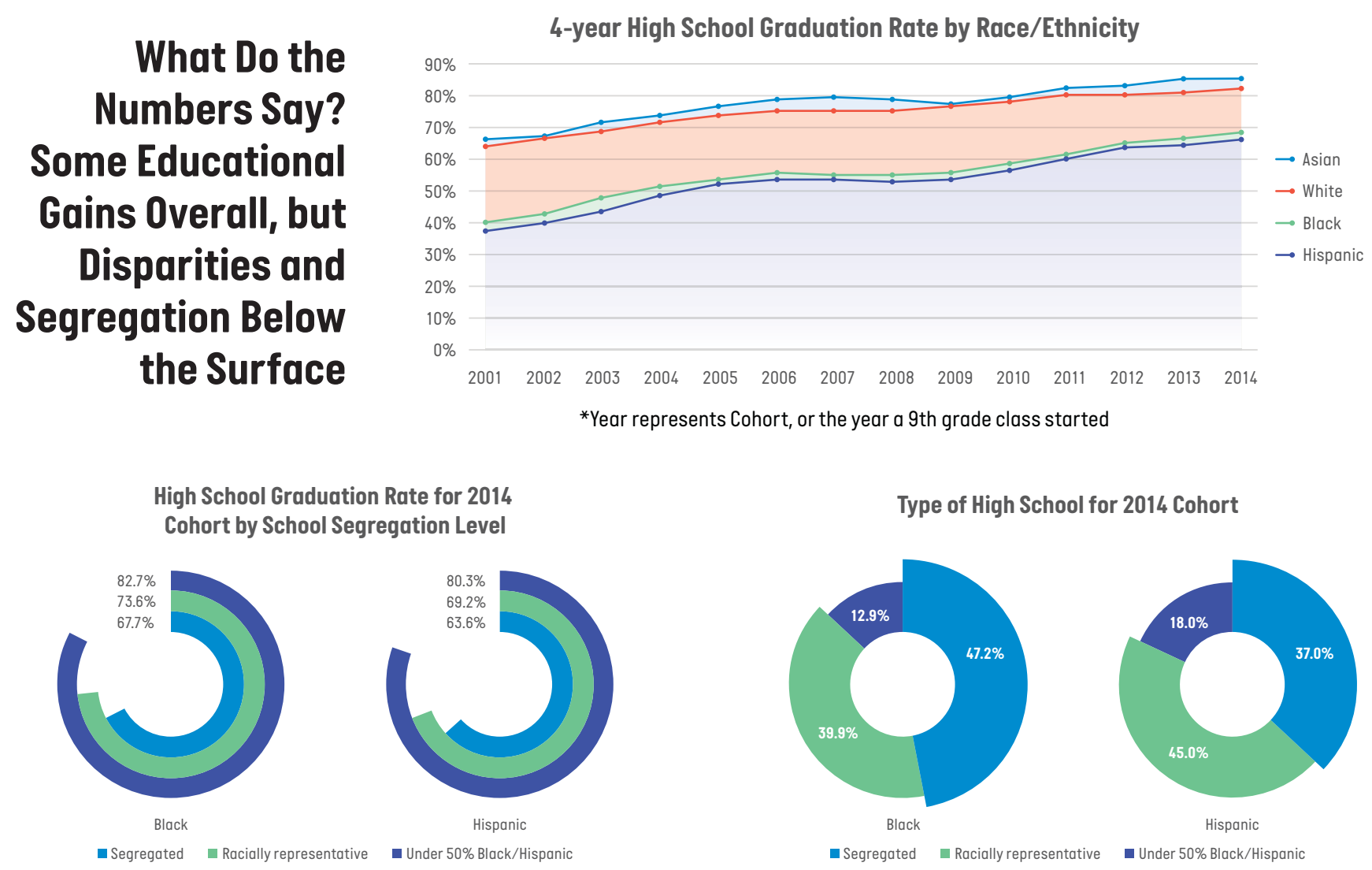

Type of High School for 2014 Cohort

For the purposes of our analysis - and consistent with NYCDOE guidelines - segregated schools are defined as those where the combined share of black and Hispanic students is $90 \%$ or higher. Racially representative schools are those where the combined share of Black and Hispanic students is between $50 \%$ and $90 \%$. 


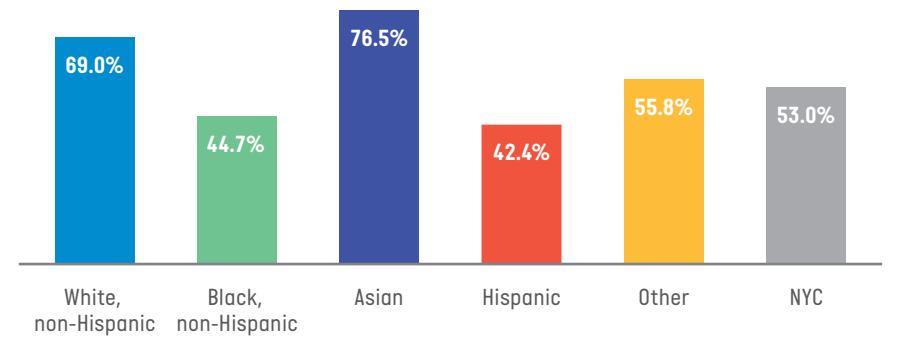

Analysis excludes young people who are still in high school or who have earned a 2 or 4 -year degree

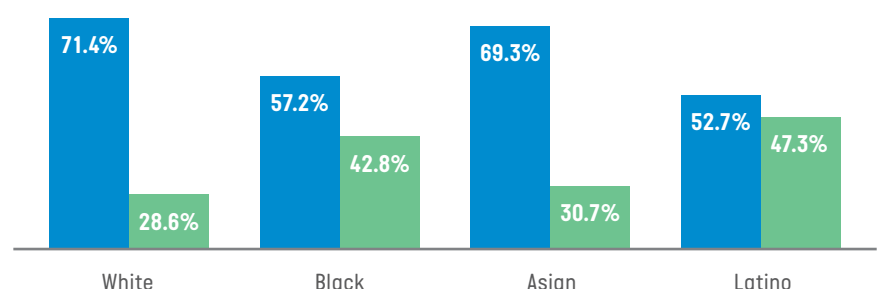

- Senior colleges Community colleges

Similarly, college enrollment rates, despite increases across groups, also show notable disparities by race and ethnicity. White and Asian students remain more likely to enroll in college, and are more likely to do so at fouryear schools, which have much higher graduation rates than those of two-year colleges.

Share of under 35 NYC high school graduates who enrolled in college and left without a degree

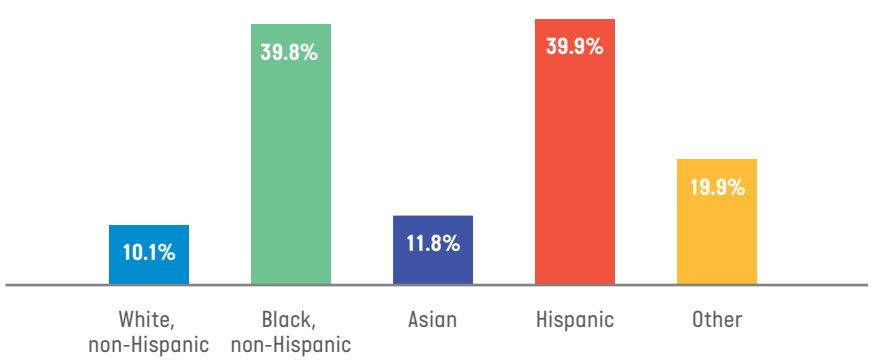

Unemployment Rate for NYC 25-34 Year-0lds

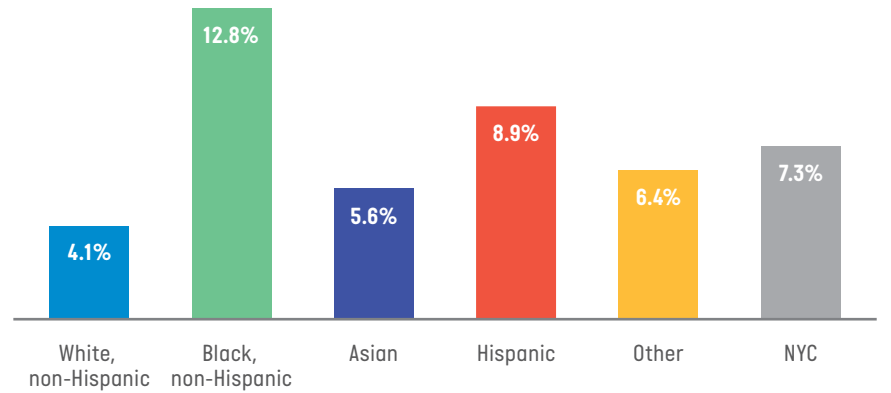

These differences in high school graduation and college enrollment play out in disparate college completion and employment outcomes for young people across racial lines. White and Asian students are far more likely to complete a college degree than black or Latino students after they enroll. Among NYC residents under the age of 35, black and Latino residents who enrolled in college were nearly four times more likely to leave school without a degree compared to their white and Asian peers. 


\section{Addressing School Segregation with Work-Based Learning}

The most straightforward way to address segregation is through enrollment-focused integration efforts. As the Supreme Court ruled in 1954, the United States has never been able to offer equal services to separated racial subgroups, and today's outcomes continue to reinforce this finding, 65 years later. To its credit, New York City has engaged in a series of recent projects to examine and explore ways to diversify its public schools, including grassroots, school-based; district-level; and citywide initiatives. Each of these have encountered strong resistance, even when they have been backed by research or seek to make only small changes to larger enrollment systems. These efforts are ongoing and should be supported. At the same time, those interested in the success of all students should continue to seek programmatic investments and policy efforts to mitigate the challenges of segregation and disparate outcomes.

To the extent that high schools serving high proportions of students with historically lower outcomes have additional resources, these are often used for academic supports in core areas. ${ }^{8}$ These classroom efforts are vital but insufficient. The differences between schools that serve higher and lower income students go far beyond academic instruction. The movement to create and expand Community Schools, which seek to address other issues faced by low-income students and their families, should be part of any effort to increase equity. But there are other programmatic opportunities that get at the heart of what happens when students from notably separated communities attend separate schools, where their isolation is heightened.

HERE to HERE believes that some of the most adverse effects of segregation relate to the differences for students at distinct schools due to the networks of parents and adults associated with each school. At schools attended by students from families with higher incomes, students are connected through social networks to adults with a wide range of professions and ties to postsecondary educational institutions. At schools dominated by students with lower incomes, students have access to adults with a much more constricted range of professions, jobs that are concentrated in fields and occupations that pay less and have less authority, and relationships with fewer and less selective colleges and postsecondary programs. ${ }^{9}$

Students in higher income households with access to a richer professional network often get the opportunity for experiences - such as internships, mentoring, and job shadowing across a wide range of professions - that allow them to better explore and understand who they are and who they want to be, along with baseline knowledge of the types of jobs and careers that may be available to them. Such exposure and knowledge complement traditional classroom learning, and can offer students powerful insight into what is possible for them in terms of career goals, and which postsecondary programs can put them on track to achieve them.

WBL programs can mitigate some of the most deleterious effects of segregated school environments by enhancing students' social networks, and providing them with the knowledge and experiences that they might have otherwise gained if they came from a family with more resources and connections, or attended a school with those networks. Enhanced WBL programs can also provide strong benefits to students in schools with richer social networks, by providing opportunities and resources more intentionally and directly to students than is currently the case.

HERE to HERE believes that all schools should have more resources dedicated to supporting all students in these activities, which have been shown to provide students deeper connections and relevance to their high school experiences, as well as much more tangible pathways to successful postsecondary transitions.

\section{What does the research say? The tangible benefits of work-based learning}

These beliefs are based on research from a range of existing studies, as well as new work conducted by HERE to HERE. An MDRC examination of the hundreds of small, thematically-oriented high schools that replaced many larger schools in New York City at the start of the 21st century found positive effects on students, as have studies of local Career and Technical Education [CTE] schools within the small schools portfolio. 10,11 Even New York City's Summer Youth Employment Program [SYEP], despite lack of connection to school-year activities for participants until very recently, has shown benefits to high school students in terms of increased attendance and test scores once they return to their classrooms in the Fall, compared to students who do not work in the summer. ${ }^{12}$ One reason for the benefits cited in these studies includes the increased engagement and relevance of coursework to students in these schools, echoing national studies into career-related high school programming which found similar benefits. ${ }^{13}$ 


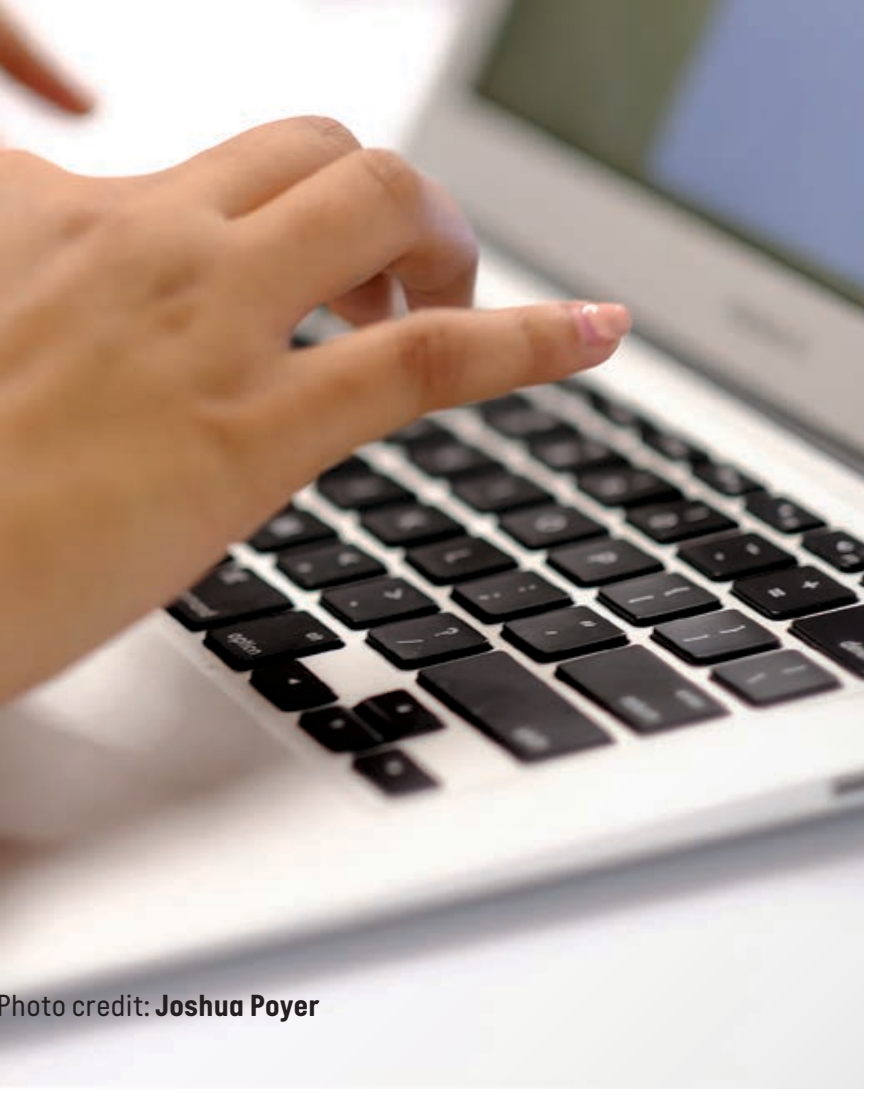

\section{What do the numbers say? Isolated communities are creating different starting points for students before they enter school}

Demographic data about New York City residents show massive opportunity gaps between families of students based on their income and race when it comes to who they might know. Low income and students of color come from families with connections and networks that are much less oriented toward higher education and betterpaying jobs. Sixty percent of parents of white students have college degrees [and overwhelmingly Bachelor's degrees], compared to $29 \%$ and $19 \%$ of black and Hispanic parents, respectively. ${ }^{17}$ This means access to networks and relationships that provide clear examples of what college means in the lives of real people

\section{Educational Attainment of Adults in Households with Children}

At the college level, research has found benefits of similar activities, and we are particularly influenced by a study from economists at the University of WisconsinLa Crosse, the University of Pennsylvania, and Auburn University that found that internship experiences during college have a much greater effect on a graduate's employment prospects than their choice of major, even when majors are in the field of the specific job being sought.14

A common refrain is that "who you know" is as important when it comes to lifetime prospects, particularly in relation to employment, as "what you know", the content and skills gained through educational preparation. Research supports this common knowledge, finding that the renewed focus on content [what you know] in education policy over the past 20 years has not closed achievement gaps as much as expected, and that efforts to develop students' abilities to strengthen and expand their relationships and social networks might offer a more fruitful approach. ${ }^{15}$

This and related research has galvanized a new focus on how to expand access to internships and enhance the types of programming referred to as work-based learning, career pathways, career-connected learning, and other names, ${ }^{16}$ in this report, we will use the term work-based learning [WBL] to capture this range of activities, and be more specific where necessary.

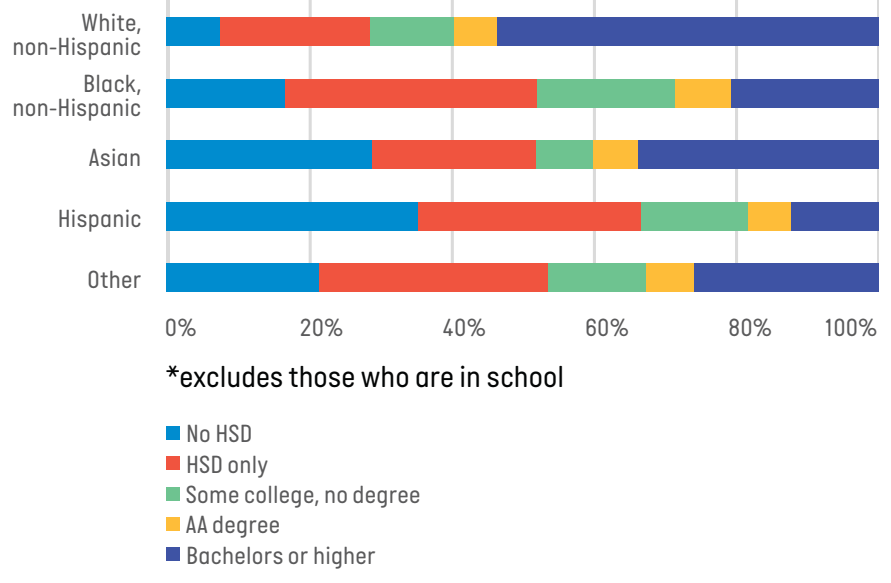

In addition to lacking a network of adults who have had successful college experiences, young people of color are also much less likely to have any exposure to the types of careers that pay well, for which college is particularly necessary. Just 15 percent of black and Hispanic parents in New York City work in high paying fields, such as Law and Finance-less than half the rate [33 percent] of white parents. ${ }^{18}$

Though black and Hispanic children may have access to other adults in the household [including grandparents and other relatives], we described in the previous section that these adults typically have less experience successfully 
navigating college and exposure to high-paying careers. This is compounded by the dynamics of residential segregation, meaning that the friends of these children also have fewer adults who can provide college and career guidance in their household, and so forth. The result is that children of low-income and black or Latino parents have much more economically constricted networks of adults in their lives, and that those adults are much less likely to have social capital currency, in the form of college or career experiences, that can offer value to young people as they develop their educational and career trajectories.

Even the new generation of small high schools in New York City, which, as cited above, have been found to increase graduation rates of low-income students, act to shorten the networks of the students who attend such schools. Twenty-two percent of black high school students attend schools with a total enrollment of 400 or fewer, compared to just six percent of white students. ${ }^{19}$

There is a field of research to support the idea that these networks have significant value to young people transitioning into college and careers. The research on the power of social networks is robust, dating back to work in the 1970s attesting to the "strength of weak ties", the importance of how relationships, particularly those outside of family and close friends, are particularly powerful in opening doors to economic opportunities. ${ }^{20}$ The recent study that internships offer a greater chance of job placement success than college field of study leads us to believe that the richer professional networks of higher income students lead to tangible benefits, in the form of internships and related career exposure opportunities, that are clearly less available to students further down the income spectrum. And anecdotally, we know that higher income parents are aware of and use their connections to provide their children with precisely these opportunities. ${ }^{21}$

Our qualitative research finds that rather than intentionally seeking to mitigate these differences, our schools are perpetuating and heightening them. The question is whether our school systems recognize this dynamic, and are willing to work to address it, even if it means hard choices about redirecting existing funding and changing policies.

\section{What do the students say? There are marked gaps in the social networks that can provide information and access to work-based learning. And that schools are worsening the problem.}

The findings of our labor market analysis are clearly reflected in the comments of the high school students we interviewed for this project. ${ }^{22}$ Students from higher income backgrounds reported knowing adults with a broader range of careers in high paying fields and an ability to access those connections in their personal educational trajectories, compared to lower income students, who reported much more limited college and career-related social capital within their networks of adults. And students report that these differences are heightened in their high schools, which offer disparate levels of work-based learning opportunities to students. Yet students from all points on the income spectrum showed an understanding of the value of work-based learning experiences in their education.

\section{Marked gaps in social capital}

Students from higher income families, who tend to attend schools with relatively higher concentrations of white students, ${ }^{23}$ have many more connections and opportunities through their families, and the families of their friends. There are clear differences in the extent to which students from different backgrounds know adults who hold different types of jobs. Students at higher income schools cited knowing doctors, lawyers, finance professionals, and elected officials, either in their own household or in the households of their friends. Lower income students rarely cited knowing adults in any high income professions, and were much more likely to name adults working in retail and other hourly jobs. Lower income students rarely even seemed to know the occupations of their friends' adult family members.

Higher income students enter high school with more knowledge and clarity about college, largely due to the fact that their closest family members are college graduates. Higher income students were much more likely to name their parents as the people they would consult with questions about careers or higher education. Lower income students were much less likely to say they knew college graduates, and if they had a question about college or careers, they would be much more likely to ask such a question of a teacher or staff member at their school, rather than their parents. 


\section{Disparities in existing social capital}

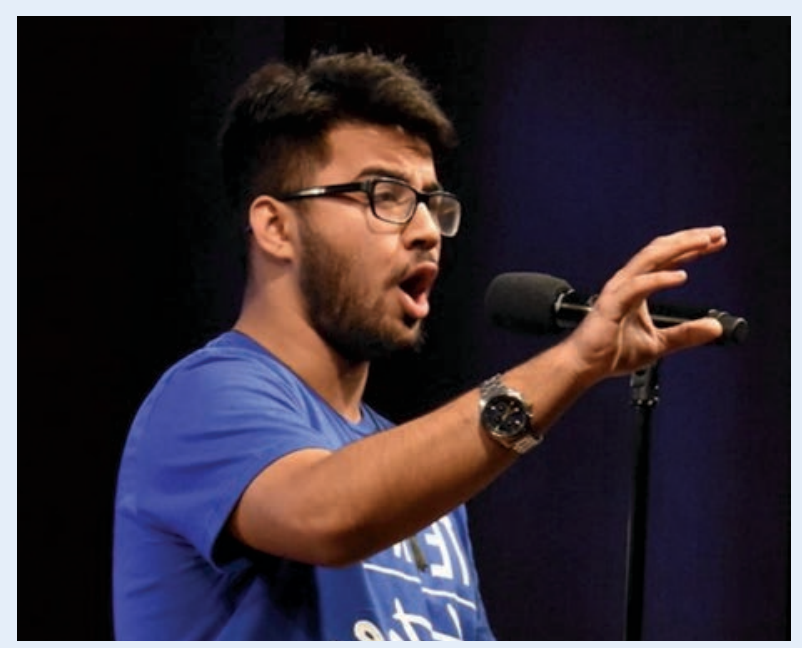

R. Compare me to a kid whose dad is friends with like an engineer, a lawyer and a doctor, and that kid goes to his dad, and like dad have a career question, his dad can pick the phone up, and boom, that's a meeting set up. $y$

\section{-Deen}

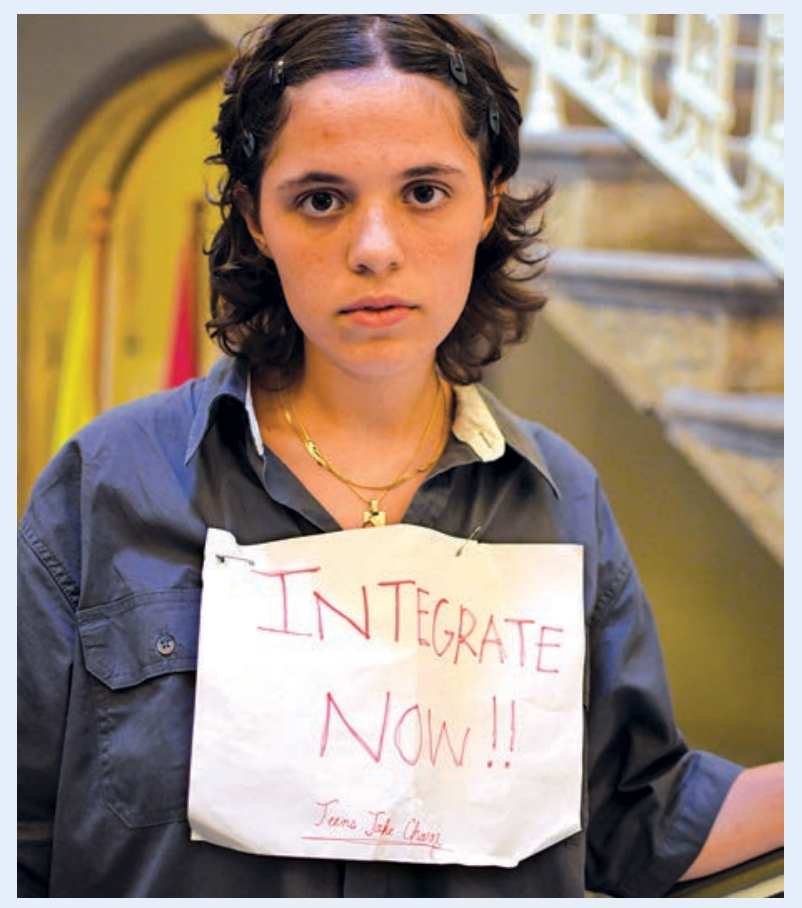

TP One of my friend's mom is a psychoanalyst. One of my friend's dad is a lawyer and her mom is in publishing and used to work at a bookstore. One of my friend's mom is also a lawyer. gy

-Nora
Interestingly, students at higher income schools were very aware of these differences in opportunities, and how they would impact the success of different groups of young people. Conversely, lower income students were much less likely to articulate an awareness about the extent to which their more limited social networks might hinder their future success.

\section{Schools reflect and heighten existing disparities in WBL opportunities}

Students report that the programming in their high school not only reflected, but heightened these differences. In the broadest sense, students at higher income schools were able to articulate that their schools focused on three main outcomes: graduation; personal growth and exploration; and helping students build a resume that would allow them to be more competitive when it came to college admissions and employment. Young people who attend schools with higher concentrations of lowerincome students claimed that their schools generally had a singular emphasis on graduation.

The opportunities provided to students at their schools reflect these different types of focus.

Students at multiple schools that serve mostly higher income students report that their school had a mandatory internship requirement; no students who attended a low income school cited such a requirement when asked [at least one of these schools does, in fact, have a mandatory internship requirement, but the fact that students we interviewed were not aware of it is a finding in and of itself]. Many students at lower income schools did participate in internships and other WBL experiences, but they reported that those opportunities were limited to a select group of students, and not offered universally, as they were in higher income schools. Students reported that the selection of students at lower income schools to receive WBL opportunities tended to track them along academic performance, with interviewees claiming that students who didn't thrive academically or otherwise show strong potential rarely had such opportunities presented to them. Those who did receive WBL opportunities at lower income schools tended to do so thanks to the support of an external organization, such as Seizing Educational Opportunity [SEO], rather than from a program embedded within the school, utilizing school staff, as was the case at higher income schools. 
"Many students at lower income schools did participate in internships and other WBL experiences, but they reported that those opportunities were limited to a select group of students, and not offered universally, as they were in higher income schools."

\section{Disparities in WBL opportunities at school}

FT The options are very limited in my school. I was very fortunate when it comes to internships and jobs, but I know a couple of other students who weren't. They would ask me 'Does your law firm have another position? Can I apply? How do I get an internship or a job?' I was very fortunate. But, as I said, there are other students who were asking. They always say 'I've been applying to 30 different jobs and not hearing back from them. The school's not helping me get internships.'

\section{-Bissiri}

T/ feel like there's a disparity of opportunities in communities of color for internships and careers that are not like electricians or plumbers. But there's not that many opportunities for internships in Iaw, medical accounting. There's a big disparity. 98

-Crystal
Students felt that their WBL opportunities were important and influential to their next steps in terms of college and careers, clearly articulating how work-based learning experiences would allow them to be more successful after high school. Students at low income schools who did get access to the limited WBL opportunities offered to them as high achievers were quick to cite them as very beneficial. They cited personal exploration and growth as overriding benefits of WBL activities, and how this would allow them to make more informed college and career choices. It was clear that for lower income students, WBL was able to fill in the gaps from the limited social/ adult network with which they began high school. Several higher income students we interviewed found their required internship experiences so meaningful that they continued them, without pay, beyond the hours required by their school. The ability to take an unpaid internship is a privilege in and of itself, and clearly distributed along economic lines. ${ }^{24,25}$

\section{"It was clear that for lower income students, WBL was able to fill in the gaps from the limited social/ adult network with which they began high school."}

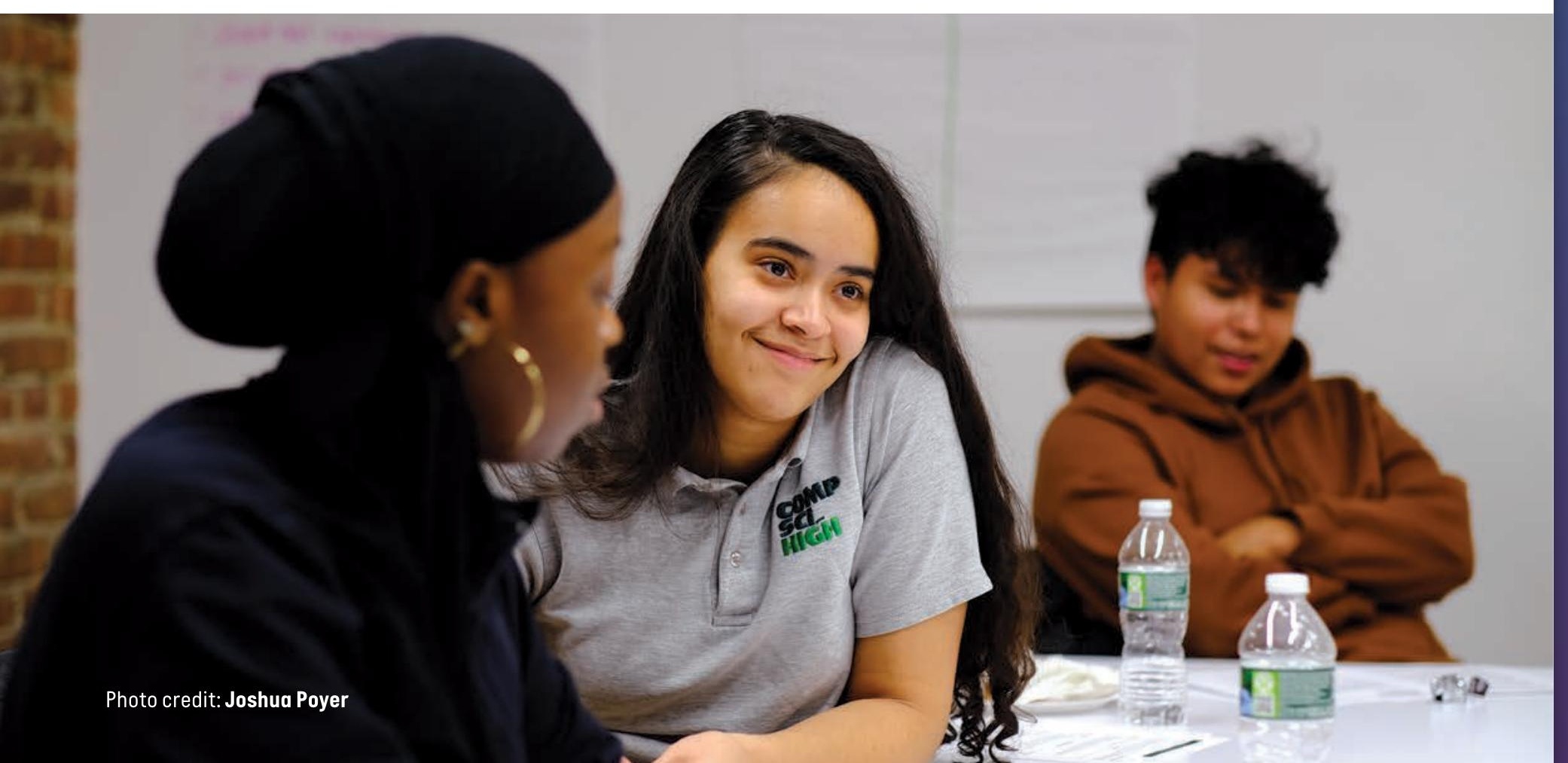




\section{All students recognize the importance of Work-Based Learning}

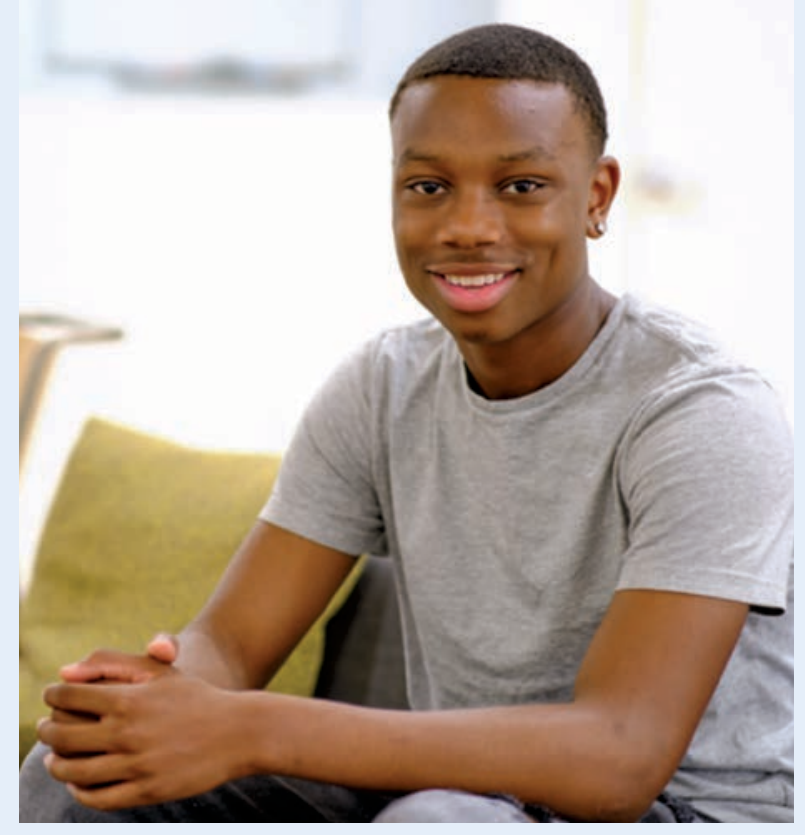

T. [My internship] is helping me gain more communication skills and marketing skills. Because I want to be in business field when I am older and when I go to college, and this is one step closer to me achieving what / learned in school.gy

-Jai'one
N When I started high school, I wasn't really aware of what I wanted to do. I knew I loved to write, but I didn't know how to make work out of it. And there were things that I was passionate about. But I didn't know how to make a life from them. So I think these opportunities have really shown me the variation and how your life can look-it doesn't have to be one set path, you can enjoy the things you do. For me, that means you can want to write and you can combine your passions and make a career for yourself. 5

-Aniya

T. I feel like prior to high school, one thing that, prior to 10th grade, something that I was really oblivious to was the whole nonprofit world. And I feel like it was a very interesting thing to dip into; the internship that we're currently a part of now. It's very nonprofitoriented work. So it was really interesting to see how nonprofits run and company logistics that you would never be able to see, unless you are actually working. So I feel that, instead of waiting until after college, I'm really grateful that I had the opportunity to learn about the nonprofit world now. 98

-Omar

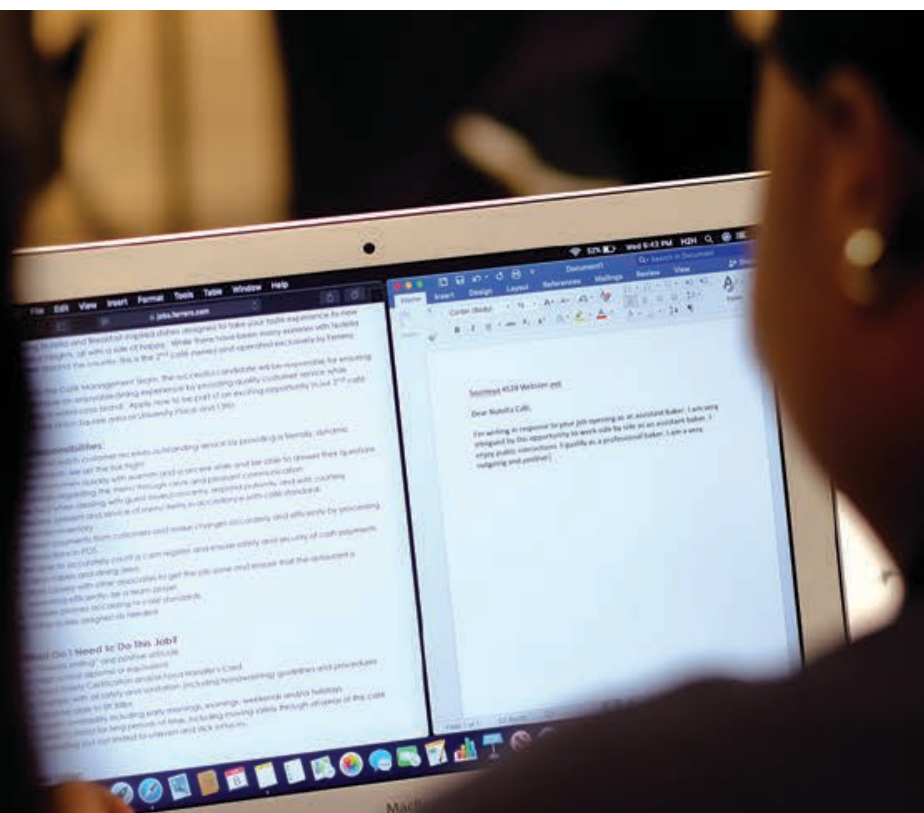




\section{How Might WBL Be the Approach to Equity That We've Been Missing?}

One area that clearly indicates the importance of work-based learning is the essays that high school students write for college applications. Results from any internet search for guidance on college essay topics advises students to identify a meaningful personal experience that has allowed them to learn who they are, with emphasis on how they have adapted to challenging new experiences. It is hard to find a source arguing for students to use classroom academic experiences, with the logic being that this area is already represented in a student's transcript. Yet it is clear that students from households with different levels of resources have far different types of access to the experiences and reflective opportunities that provide information to students about who they are, and ways to illustrate that neatly to colleges.

Students from families with resources can write about experiences such as community service projects, an internship, or travel abroad in a way that shows who they are, the clarity of their goals, and how their preferred college can serve to build on that. Students with more of these experiences have more material with which to convince colleges that they know enough about themselves to create a coherent narrative about how this specific college, or better yet, a unique course of study within that college, represents the clear next step in the fulfillment of a larger story of success. Lower income students, despite having their own powerful lived experiences, may have less of a chance to translate them in structured ways to inform their own decisionmaking, or to create narratives about their goals and identity. Very few college essays discuss things that happen in math or science class, or during Regents prep, even though those activities represent a larger share of lower income students total high school years experience.

Work-based learning offers the chance to level that playing field by giving students, all students, the two sets of information that currently represent this equity gap, and which are complemented by access to an expanded social network. First, they offer students insight about what is inside them: who they are, their passions, talents, and interests. Through WBL, students can learn about the tangible things that they are good at, what they enjoy doing, and what they think are important. Do they want to work in an office, or would they prefer to be outdoors? Do they see themselves in the corporate world, or in a different setting? What aspects of the world of work are appealing to them: sitting in front of a computer, talking to people, or building a new product?

Second, WBL provides students with a much more tangible set of information about what's out there: jobs, careers, and how advanced levels of education and training really play out in the world of work. Through work, young people can learn about not only different types of jobs, but see how the adults who hold them have different levels of education, experience, and skills that can be developed through different types of postsecondary training or education. And as the data tells us, low income young people are far less likely to have access to this type of information through their own social networks, where adults hold fewer and more constricted types of jobs, which are more likely to be low paying. It becomes much easier to plan to be a doctor or lawyer or a data analyst when you know a person with that job; conversely, it is not only less clear how to obtain such jobs for low-income students, but if they have never known a job exists, or met anyone who looks or sounds like them in that field, it may seem completely out of reach.

Work-based learning experiences not only help students get into college, but they also provide the skills needed to navigate their next steps in both postsecondary education and work. There has been a range of research showing that as much as academic preparedness, the "essential" or "soft" skills that students gain through work allow them to be successful once on college campuses and in workplace settings. ${ }^{26,27,28}$ This is particularly true in New York City, where a majority of students work while attending college ${ }^{29}$ and need to manage their time efficiently and interact with a range of supervisors and advisors.

Work-based learning has the potential to significantly enhance postsecondary learning at a more advanced level, where students may be further along in their thinking and exploration of careers. Employers can provide opportunities for curriculum design and instruction in the campus environment, and more valuably, offer the chance for applied learning in the 
workplace. In countries such as Switzerland, students do not face a tradeoff between work and higher education; two-thirds of students pursue education in an apprenticeship system where they can earn money, learn skills, and put themselves on career pathways, while also gaining postsecondary accreditation that they can put toward a degree.

At CUNY, where 53 percent of students already work while attending school, largely in jobs that are not intentionally connected to their course of study by the university, there is a clear opportunity to better braid school and work. Graduation outcomes are low in both community and senior college settings at CUNY. ${ }^{30}$ In interviews conducted for this study, ${ }_{1}{ }^{31}$ non-completers cited two main reasons - outside of cost—for their lack of success in college: first, a lack of skills related to time management, navigating the demands of the more complicated administrative environment of college as compared to high school, and other non-academic skills. Second, they noted the lack of connection between much of their coursework, other activities on campus, and their career interests.

"Non-completers cited two main reasons-outside of cost-for their lack of success in college: first, a lack of skills related to time management, navigating the demands of the more complicated administrative environment of college as compared to high school, and other nonacademic skills. Second, they noted the lack of connection between much of their coursework, other activities on campus, and their career interests."

College non-completers felt that internships and other work-based learning activities represented direct ways to address both challenges. Internships, specifically, provide the chance for young people to develop the time management, communication, and other skills that are essential to succeed in college in ways that traditional high school classroom instruction is unable to provide. Higher income youth, who are more likely to have had those experiences either on their own or because their high school has a more robust set of opportunities, often get those skills as part of their high school experience. But lower income young people often arrive at college or their jobs after high school without the preparation to succeed in those environments. Even college preparation courses, which many students do receive in high school, in advisory or other programs, are largely theoretical, and do not give students a hands-on chance to learn and develop those abilities as well as the context for understanding why such skills are important.

Second, both students who completed college with a diploma and those who did not that we spoke to for this study were quick to recognize how an internship during college, particularly one that was related to their field of study, could help them feel more engaged, connected, and more likely to complete. All of the graduates that we spoke to cited some type of hands-on learning experience during college, an internship, volunteer initiative, or other program connected to their academic experience that both provided them with a clear sense of meaning, and a deeper understanding about the direction of their studies. All of the 12 college graduates that we spoke to claimed that the major they chose was in some way related to a work-based learning experience that they had, either in college or previously.

\section{Impact of college internships:}

RT/ went to Syracuse because they made me an offer through my guidance counselor. I had not even planned to apply. I was all on my own when it came to thinking about college and I did not have any real support in making the choice. I received tutoring in college then became a tutor myself. That experience made me realize that working with young people was what I wanted to do, so I decided to major in Psychology, with a Child and Family focus. I graduated college and became the Community Programs Coordinator at a respected advocacy organization. I think too many students fall through the cracks because they think they are alone. They need more of a support system, and internships and other programs can provide that extra support. $y$

\section{- Margellin}

First in her family ever to go to college, went to Syracuse. 


\section{What's the Path Forward?}

\section{OUR RECOMMENDATIONS}

We believe that a significant expansion and enhancement of work-based learning represents the most promising way to provide opportunity to New York City high school and college students. HERE to HERE is already engaged in this work, operating or supporting a range of demonstration projects in each of these areas. The purpose of these activities is to use local and national evidence to create new proof points as we make the case for change. And although they are too numerous to name here, we must acknowledge the range of other actors in the public, private, and nonprofit sector who are also conducting important work, either programmatically, or through advocacy activities. We hope that this report supports all of our work as we build the momentum for change.

The following policy agenda represents our vision for how that change can happen, and was developed by HERE to HERE with the input of a range of individuals and organizations across sectors. We offer recommendations in three areas: embedding work-based learning into every high school; reorienting CUNY toward the career success of students across all campuses and programs; and meaningfully engaging employers to participate as valued partners in the design and implementation of our educational systems. The result of this work will be an employer-informed, student-centered model of talent development where young people have more and deeper opportunities to learn about what drives them, and how to actualize that knowledge in ways that put them on a path to successful and choice-filled lives, helping to generate economic success for employers, and inclusive, shared prosperity for all New Yorkers.
1. K-12: A Work-Based Learning for All Agenda

\section{Postsecondary: A CUNY Career Pathways Success Strategy}
3. Engaging Employers in the Design of Talent Development

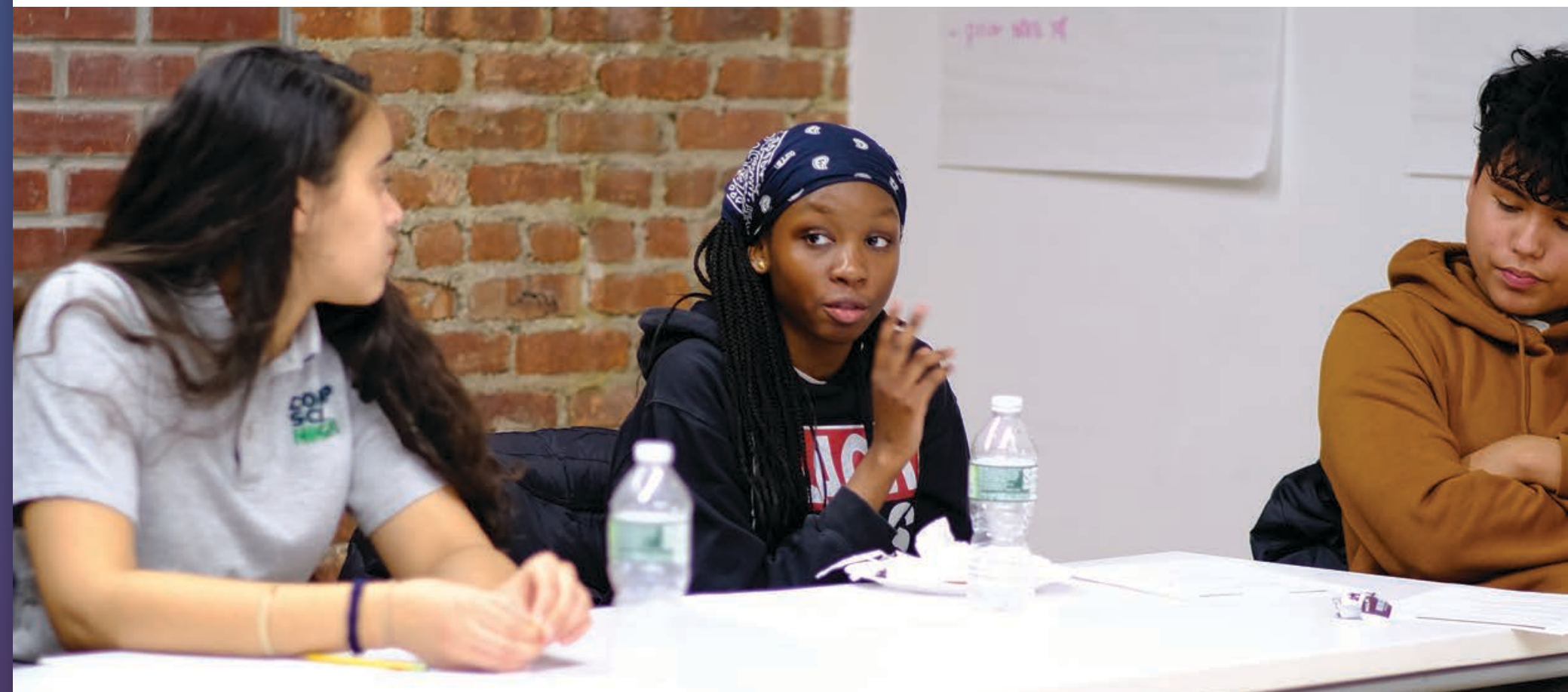




\section{K-12: A Work-Based Learning for All Agenda}

A major expansion of Work-Based Learning [WBL] at the high school level would include two major investments of resources and support:

- Expand student WBL experiences based on the CareerReadyNYC Framework and Positive Youth Development: All high school students should have the opportunity to engage in career exploration activities in 9th and 10th grade that will allow them to develop interests that they can try out in internships and related experiences after the 10th grade. Structured advisory programs based on coherent world-of-work curricula in high school offer a clear opportunity for these efforts.

All high school students should have the chance to complete at least one paid internship by the end of their junior year. HERE to HERE believes that continued growth of school-based SYEP represents the most efficient way to achieve this goal. By redirecting existing city funds for summer jobs into high schools [using existing and new $\mathrm{CBO}$ contractors], we can ensure these experiences are student-centered and employer-driven in ways that neither traditional SYEP, nor existing ad hoc internship programs in high schools have been able to deliver. We believe the ultimate goal should be the reimagining of high school as a year-round experience, with the creation of an optional paid summer internship available to all high school students, for all four years, along the lines of this proposal and implementation study.

- Change school culture and systems to support WBL, through dedicated staff and accountability mechanisms. HERE to HERE's early work to demonstrate the power of WBL in our network of ten high schools, and the growing body of research cited earlier, have illustrated the need for schools to embrace career readiness and work-based learning as part of their design, alongside traditional academic coursework. Elements of successful WBL includes dedicated, trained adults to provide schools and students with opportunities, during the school year and summer, that build off and toward each internship experience, as well as support towards postsecondary transition so that students can be fully informed about the world of college and careers that await them. We see this happening in two ways: [1] creation of a funded position in schools responsible for coordinating WBL activities, and [2] support for programmatic and accountability mechanisms that make WBL measurable and sustainable.
The first may take the form of a new funding stream for school-based Work-Based Learning Coordinators at every high school, who are charged with supporting career exploration activities, internship placement and development, and liaising between CBO SYEP partners, local employers, and school staff. In the model of the Parent Coordinator, these positions would open up the school to a range of resources to enhance student experiences, while also providing an individual with the capacity and responsibility to integrate these efforts into teacher curricula and classrooms.

Relatedly, we support exploration of and increased support for accountability mechanisms that ensure that this work is not an "add-on" for schools, but rather part of a sustainable student support strategy. One possible method for this would be to encourage schools to intentionally pursue the " $4+1$ " CDOS pathway toward fulfillment of a full Regents diploma, while substituting Work-Based Learning activities for at least one Regents exam, as is now allowable in New York State. We encourage schools and the DOE to consider CDOS as an intentional pathway from the outset of a 9th grader's experience, rather than as a fallback for those unable to pass a fifth Regents exam in 12th grade. This would allow schools to redirect resources currently being used for a fifth exam, saving them time and money that could be dedicated to a robust WBL program. ${ }^{37}$

\section{NYS GRADUATION REQUIREMENTS REVIEW}

The New York State Board of Regents has begun a process to review exit requirements for high school graduation across the state. We urge the Regents to consider encouraging increased use if work-based learning activities, if appropriately rigorous and tied to standards of quality, to replace traditional seat-time and exit exam requirements. 


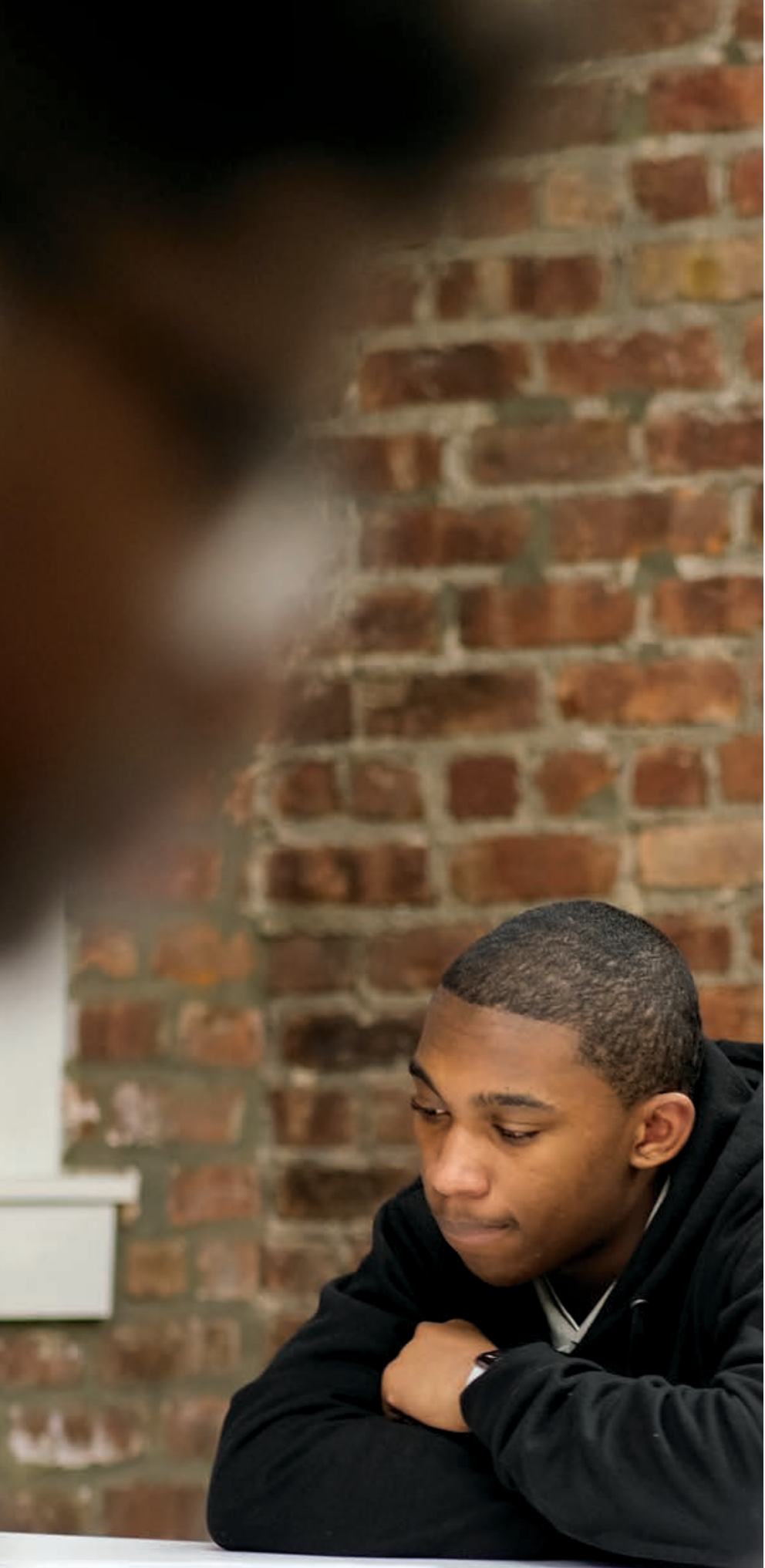

In addition, we recommend investments in the following areas to promote meaningful school culture and systems change that will support WBL:

- Recognizing there will be a learning curve for embedding WBL into school culture and teaching strategies, training and development funding to support WBL coordinators, school leadership, and teaching staff for school redesign and implementation will be critical along with investments in supporting technology and infrastructure. Use of Advisory to implement WBL curricula and supports offers another way to build off of existing structures, rather than adding on to a school's responsibilities.

- Problem solving, strong communication and writing skills, collaboration, design thinking, and ability to learn in non-academic settings are increasingly what employers are identifying as critical skills for entry level hires in promising career paths. Supporting schools in developing curriculum, either in advisory or courses, to help students gain these essential employability skills is also important to expanding WBL. Additionally, the NYCDOE should develop more curricula and courses such as the Ethnographies of Work College Now pilot to give students a deeper understanding of our dynamic labor market, how to analyze it, and greater agency to navigate it based on their individual passions, interests, and talents.

\section{- Selecting and investing in a critical number of} 40 high schools throughout New York City to hold up as exemplars so that we can demonstrate and examine best practice as well as gain momentum with employers and policymakers. The following section provides details on how a robust 40-school pilot of WBL for All might look. 


\section{Work-Based Learning for All in K-12}

\section{WHAT WOULD IT COST?}

\section{Expand student experiences:}

New York City already spends $\$ 150$ million per year on SYEP, for about 75,000 slots. Eighty-five percent of these, about 60,000 , already go to high school students. For an annual program that offered an internship each year of school, we assume that about half of the 320,000 high school students would want to participate; 160,000 students at approximately $\$ 2,500$ per internship [representing an average of older and younger youth wages and fees to CBO contractors-slightly higher than average SYEP costs for additional support] would cost about $\$ 400$ million per year. This represents about $\mathbf{\$ 2 5 0}$ million in new funding to SYEP. For a more limited program that offers a paid summer experience for two summers [one summer, after 9th or 10th grade might focus on career and college exploration, with hands-on experience doing community service and a second summer, after 11th grade, might consist of a more formal work experience], the cost would be half as much.

\section{Change school culture and systems to support work-based learning:}

A fully paid Work-Based Learning Coordinator at each high school earning the average teacher salary would cost $\$ 72,000$ per year. At 450 high schools, this would cost approximately $\mathbf{\$ 3 2 . 4}$ million per year. These estimates could be adjusted based on the rate of the position pay or other factors, including any school matching of fundsand a second summer, after 11th grade, might consist of a more formal work experience], the cost would be half as much.

\section{Piloting Work-Based Learning for All in K-12:}

An initial rollout of WBL for All could test how school-based internships and WBL coordinators, taken together, can transform a school and its local community. We recommend a pilot of 40 high schools in the Bronx [or citywide], which would allow for the range of school and student diversity. If we were to target an intentional expansion of a NYCDOE program similar to School-Based SYEP to those 40 schools, that would cost approximately $\$ 10$ million [100 slots per school $* \$ 2,500$ per slot * 40 schools]. In order to ensure that schools have the capacity to successfully administer such an effort, and align it with academic and other programming within the school, we recommend the funding of a WBL coordinator at each of those schools, which would cost approximately $\$ 2.8$ million $[\$ 72,000$ FTE salary * 40 schools], to which we would add benefits and technical assistance, costing about $\$ 1.2$ million. The total for a robust, fully supported rollout at 40 schools would be $\$ 14$ million. 
In terms of other areas, the NYCDOE will need to invest in centralized coordination and assistance to WBL activities in and across schools. While both the NYCDOE Office of Postsecondary Readiness and Support [OPSR] and the Office of Community Schools [OCS] have significant expertise that could be leveraged to support the expansion of work-based learning, overall there is not enough capacity for training and professional development to support the WBL coordinators. Additionally, to truly achieve equity and promising pathways to opportunity through WBL will require a school redesign that embraces systems and structures of support within a school beyond a single WBL coordinator. As a result, we would recommend allocating additional funding to OPSR and OCS to support schools in their redesign process and the technology platforms such as the New Visions Career Readiness Data portal that can facilitate such school change efforts.

Another model for the NYCDOE to consider is the one currently in use by the Brooklyn STEAM Center, which partners with eight high schools to provide hands-on learning experiences for 11th and 12th grade students in five industry pathways. Students attend classes at their standard schools for part of the day, then travel to the STEAM Center where they actualize academic work in classrooms that include 3-D printers, high tech kitchens, audio and video recording studios, manufacturing, and more. Students have adult mentors, participate in internships, gain meaningful skills, and are able to try out a range of different job activities. Currently, the Center is only able to offer elective credits, and is operated as a program, without per capita student funding. We recommend that the NYCDOE work with industry to develop a replicable funding model for this important type of public/private partnership. The Center offers a glimpse into a future where every student has the chance to attend a traditional high school for part of the day, followed by an Applied Learning Center where they can actualize those learnings in a more professional setting, with even greater integration of traditional coursework.

\section{Postsecondary: A CUNY Career Pathways Success Strategy}

Postsecondary institutions play a dual role for students: in identity formation, by helping students learn about themselves and the world, as well as human capital creation, by imparting the skills and economic signals necessary to begin careers. Our public postsecondary systems, such as CUNY, can be supported to do more in both areas, particularly for low-income students who lack the benefits of access to benefit from social connections and enrichment experiences that are more available to higher income students. CUNY, already well-recognized as an engine of economic mobility, has the opportunity to transform itself into a national model for 21 st century talent development by orienting toward the career success of its students, and taking better advantage of its proximity to one of the most diversified and robust economies in the world.

Ultimately, that will require three major, interconnected changes:

1. Changes in how credits are issued so that work experience, if aligned with a field of study toward the development of specific competencies required for careers, is on equal footing with classroom theoretical instruction;

2. Growth of and increased emphasis on degrees in applied fields and specific occupations that are part of the world of work [internships, certifications, and other applied projects]; and

3. Much greater involvement of employers in the design and instruction of accredited coursework.

These reforms will likely require CUNY to diversify its economic model. Currently, it relies heavily on student tuition and fees, as well as public support, neither of which have incentives that align with career development outcomes. In the long term, we recommend aligning incentives and accountability mechanisms that promote and support career readiness, preparation, and success more directly. In the short-term, there are several steps CUNY can take, including:

\section{- Empowered Career Offices at all} CUNY Campuses - currently, support for career development is strong in places, but inconsistent across campuses and programs. CUNY should empower these services so that they engage all students from the moment they step on to campus, working with students to think about and develop their career 
pathway, with inputs including activities in core classes, applied learning opportunities throughout the year and external work experiences that are tied to programs of study. Career counseling should include mentoring from a designated career coach, as well as connections to alumni, adjunct faculty from industry, and fellow students.

\section{- Expansion of internships and} applied learning opportunities at all campuses, across fields - there is a clear need and opportunity for CUNY to expand its use of internships across all degree programs, including liberal arts. We see this as particularly valuable in igniting the curiosity and passion of students during their first two years of study, who can become disengaged if they are taking only required courses.

In addition, bootcamps, hackathons, and microcertifications are other tools for students to develop specific job skills, both within existing courses, and during underused periods of the academic year, such as winter session and summers. These types of activities are traditionally more available in specific fields, such as IT, but should be more broadly available across courses of study. The fact that employers are often willing to use these opportunities to identify future hires is evidence of their potential for expansion.

- Credit for Prior Learning - Given that a majority of CUNY students work while attending school, CUNY should create mechanisms by which those experiences can be structured and used for credit. This would entail defining a set of skills that are available to students across jobs, and creating assignments and assessments for students to reflect on and present those skills. Recent research by Society for Human Resource Management [SHRM] finds that employers claim that college graduates lack "soft skills" such as email protocols, responding to supervisors, and time management-precisely the competencies gained through work..$^{38}$ Finding a way to make work during college bear credit offers a chance to structure and systematize how students reflect and demonstrate the skills they gain through work, while also helping them avoid the challenges of viewing school vs. work as a tradeoff. This would allow for students to gain a certain number of credits for general workplace skills, as well as additional credits that might map to competencies in specific fields of study, if their work experiences align. As part of this, we urge CUNY to consider how to leverage work-study as a strategy to pay students for relevant work experience where they can learn important transferable skills.

\section{- Career-focused seminar for all}

students - all CUNY students should take a seminar that supports career development from the outset of their college journey. This might be based, in part, on Ethnographies of Work [EOW], a two-course sequence at Guttmann Community College that engages students in theoretical discussion and in-depth investigation about the world of work, specific occupations and careers, and the skills necessary for success in each of them. Most importantly, EOW combines classroom study with intensive weekly advisement for students to explore career paths-this type of ongoing support for career success is vital.

\section{- Employers as adjunct faculty - CUNY,} like colleges nationwide, has shifted toward greater use of adjunct faculty, for reasons of cost and flexibility, particularly as public funding for higher education has decreased. ${ }^{39}$ One opportunity from this change is to connect individuals from local employers as adjuncts, offering students more insight into the actual world of work, as well as a concrete way to expand their social network in that field.

We are pleased to see that CUNY's 2021 budget request includes a set of career success initiatives that align closely with the above recommendations. ${ }^{40}$ We urge policymakers to support CUNY as it works toward these goals.

\section{Engaging Employers in the Design of Talent Development}

The 21 st century labor market demands that employers, particularly private sector businesses, commit to work more intentionally, together and in partnership with local public systems, to uphold New York City as an engine of opportunity, upward mobility, and shared prosperity. We see this commitment as a responsibility of employers because the success of NYC businesses is tied directly to the training and skills of their current and future employees. We need to ensure that companies, as well as those that they invest in and partner with, have access to educated and trained talent, now and in the future.

Businesses are a key engine of economic growth and jobs, and a unified business community has the expertise and resources to partner with educators to develop local talent into a best-in-class workforce with relevant skills and capabilities. Workplaces can offer settings 
and experiences that schools cannot, and provide young people the opportunity to apply what they learn in ways that will deepen their engagement through relevancy and self-understanding. Similarly, workplace supervisors can be mentors and expand students' social networks as well as their understanding of possible professions.

In the long term, an ideal talent development system in New York City would feature high engagement by three stakeholder groups: $\mathrm{K}-12$, postsecondary, and employers, with students at the center. Currently, employers are largely involved intermittently and as individual firms, to the extent that they are utilized at all, in the design, development, and implementation of our public education systems. As a result, employer-school partnerships are too often bespoke and unique, without possibilities for scaling. Some efforts, such as CTE partnerships in high schools ${ }^{41}$; growing apprenticeship programs ${ }^{42}$; and several promising efforts at CUNY43, show us the foundation on which to address these issues systemically.

An engaged, organized business community has the critical expertise and resources needed to partner with educators to create a world class workforce with relevant skills and capabilities. We have identified several buckets of recommendations to weave employers more intentionally into the talent development system:

\section{- Create, partner and support} intermediary organizations designed to engage employers at different levels and bring them into the talent development field efficiently, rather than through the limited efforts currently available to employers. Organizations such as the New York Alliance for Careers in Healthcare ${ }^{44}$, SEIU 1199 Training and Employment Fund ${ }^{45}$, and the HERE to HERE Business Council ${ }^{46}$ work closely with employers to develop pathways for young people into promising careers. These intermediaries and industry associations can develop a more coalesced employer voice to push for more WBL in high schools and colleges; advocate for the public resources needed to support such work in the NYCDOE and CUNY; encourage elected officials to enact policies so this work happens within, rather than outside of, our public systems; and to champion changes in employer practices.

\section{- Identify a set of occupations that can} serve as the foundation for employer involvement in talent development, through the design of apprenticeships and new applied programs at CUNY. Specific occupations may be a more useful way to organize this work than sectors, given that many types of jobs - such as IT; accounting and other business operations; and graphic design-are common across industries and sectors. Bringing employers together with postsecondary organizations and high schools to map the skills required by these occupations to fields of study and coursework for students will make education in these areas more relevant and meaningful to students, assure employers that their engagement connects specifically to their needs, and provides a structure to regularly update the occupations to reflect changes in the economy.

\section{- Employers can engage with schools at all levels to provide workplace} experiences, along a spectrum from career fairs at one end, to internships, apprenticeships, and applied postsecondary programs at another end, that align with these occupational maps. Intermediaries, as discussed above, should be supported so that employers can easily and efficiently find and develop these experiences with schools. To engage smaller firms and non-profits, we should examine what resources and incentives could be made readily available to encourage them to hire and mentor students. For example, many local small businesses want to hire interns and could provide a meaningful experiences but may not be able to afford to fully cover the wages or other costs associated with a quality internship.

\section{- Modernize hiring practices to create better outcomes and greater efficiencies for students, employers}

and the economy. Work with employers should be aimed at expanding their hiring practices so that NYC companies see NYC public high schools and colleges as their go-to resources for talent. This may require shifting the current operating procedures of HR departments, hiring managers, and executive staff. Too often, hiring does not leverage or benefit from local investment in education and training, and relies on talent from outside New York. Such a transition will require shifting mindsets and past practice including re-examining traditional reliance on alma maters and social networks, and developing more active partnerships with local educational institutions. Such behavioral change will only be successful if our public education systems offer employers a better return on investment. 


\section{Conclusion and Call to Action}

HERE to HERE is hopeful that this report will raise the volume on what we believe is a growing drumbeat for change. We are eager to partner with individuals and organizations to advocate for increased work-based learning for New York City students. We firmly believe that the recommendations of this report represent the most promising way to provide equity to students, and make our economy more inclusive. Change across the public and private systems of K-12 education, CUNY, and employers will require new policies and significant additional funding. But it must begin with a new mindset by actors in all these sectors-a mindset that more collaboration across school and work is needed to fully realize the promise of our young people. Such collaboration will provide youth with more opportunities to identify and develop their own passions and abilities, which will, in turn, benefit our workplaces and our economy, more broadly.

\section{How can you get involved?}

- Students and families: call on your school to do more to provide hands-on, work-based learning opportunities for students to turn their classroom activities into real-world experiences.

- Public officials and professionals working within education and workforce development: call on NYC DOE, CUNY, and elected officials to direct more resources and structural supports to expand WBL opportunities for students.

- Employers: engage with work based learning intermediaries and advocacy organizations, your place of work to host interns and other work-based learning opportunities, and otherwise connecting to local schools and CUNY programs.

\section{Real change will require all of our voices _please join us!}




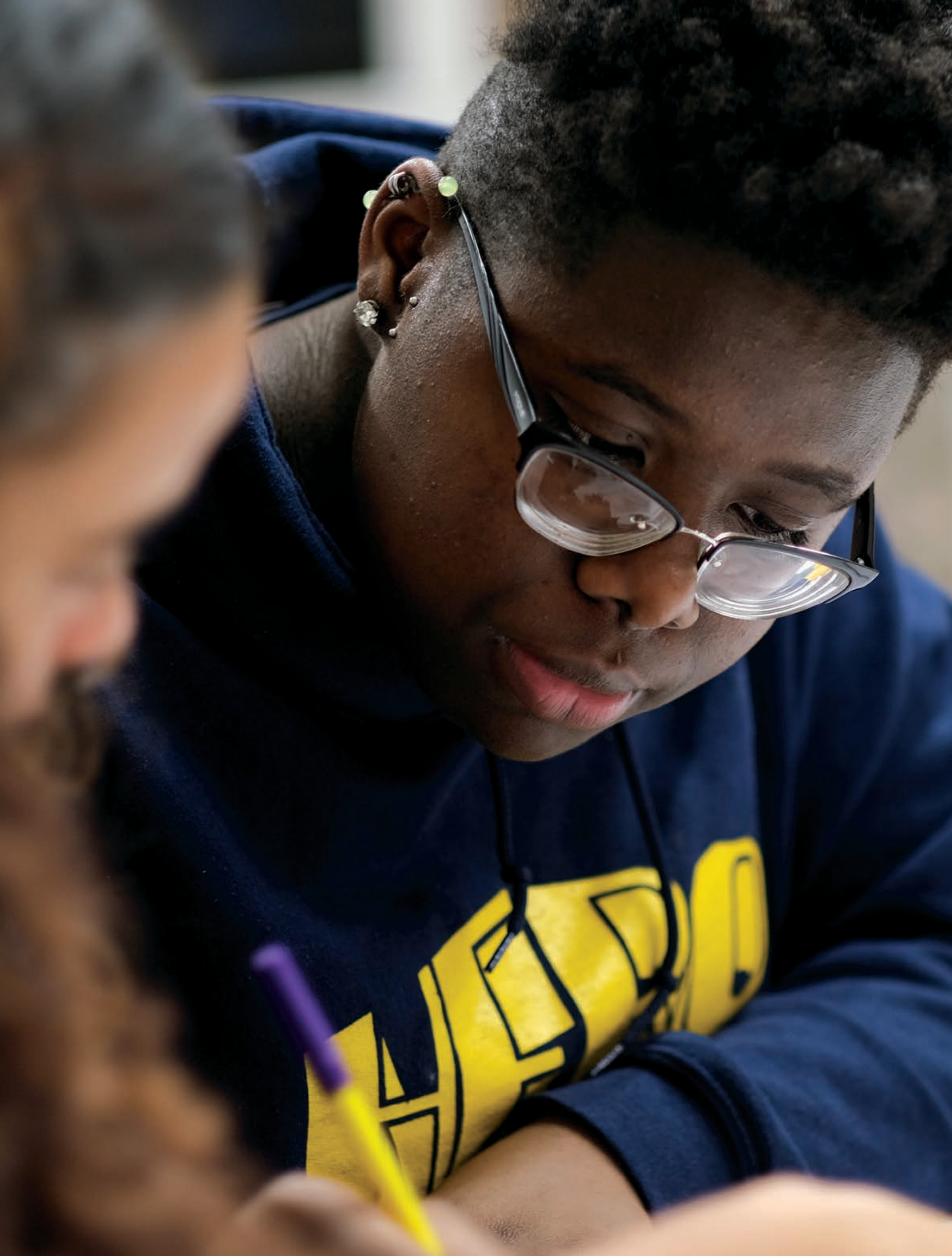




\section{Appendix}

\section{Research Design and Methodology}

The research in this study was conducted to examine the extent to which students from higher income schools, by nature of the social networks that are a part of those schools, benefit from access to a range of work-based learning opportunities to a greater extent than students from lower income schools. In theory, these opportunities support both academic achievement in high school, through greater engagement and relevancy, as well as much more fruitful transitions to postsecondary education, because such opportunities give students knowledge of both their own skills and interests, as well as information about how the steps a student takes after high school connect to a meaningful career. To test this hypothesis, this project was designed to answer the following questions:

\section{Research Questions}

- What are the differences in the educational and employment outcomes of students from different racial and socioeconomic backgrounds in New York City?

- How do segregated schools and neighborhoods mitigate, reflect, or heighten these disparities?

- How can work-based learning opportunities mitigate some of these disparities? What specific public policies and investments can support that work?

\section{Data Collection and Analysis}

HERE to HERE collected and analyzed two sets of information to answer the above questions:

- Quantitative data about the types of jobs held by and educational backgrounds of parents from different income levels. We hypothesize that lowincome black and Hispanic parents [a proxy for parents of students at segregated schools] have lower levels of education and different types of jobs than parents of higher income students, with the built-in assumption that lower levels of education and different types of jobs yield less in the way of professional networks, ability to assist children with college/career exploration, etc. In order to test our hypothesis, we examined variables from the United States Census Bureau's American Community Survey for our selected respondents, including: educational attainment; degree field; labor force participation; employment rates; and industry of employment. All data used for this report, unless otherwise specified, comes from HERE to HERE's own analysis of microdata from the 2013-2017 American Community Survey from the United States Census Bureau.
- Qualitative data in the form of interviews with high school students from different backgrounds to discuss the work-based learning opportunities available to them via their social network, school, or other related resources. HERE to HERE hired a researcher from Teens Take Charge who conducted interviews with 17 high school students, approximately half of which attended higher income schools, half of which attended schools dominated by students from households with lower incomes. The Teens Take Charge researcher asked each student a set of questions about their knowledge of and access to adults who hold jobs in a variety of fields and specific occupations. Questions also covered college-related relationships and experiences, as well as other aspects of social networks, and the extracurricular/work-based learning experiences that each student had available to them and in which they have been able to participate. Approximately half of the students interviewed were previously known to the HERE to HERE/Teens Take Charge interviewer; the other half were students from schools in the South Bronx with whom the interviewer had no prior relationship.

HERE to HERE staff also conducted interviews with 12 young people who had recently left college without completing a degree, and seven recent college graduates. Non-completers were asked about the reasons they were unable to complete their program, and completers were asked to identify some of the features that made their experience successful. 
1 Designing and Implementing Work-Based Learning, Center for the Future of Hlgher Education and Talent Strategy, Northeastern University, November 2019. https://www. bhef.com/sites/default/files/BHEF 2019 Work Based Learning.pdf. Learn more about work-based learning at www.jff.org/resources/work-based-learning-framework

2 Alex Zimmerman, "New York City touts record number of students heading to college," Chalkbeat, November 26, 2018 https://chalkbeat.org/posts/ny/2018/11/26/newyork-city-touts-record-number-of-students-heading-tocollege/

3 John Kucsera and Gary Orfield, "New York State's Extreme School Segregation: Inequality, Inaction and a Damaged Future",The Civil Rights Project, UCLA, 2014. https://www. civilrightsproject.ucla.edu/research/k-12-education/ integration-and-diversity/ny-norflet-report-placeholder/ Kucsera-New-York-Extreme-Segregation-2014.pdf

4 Kristin Black and Vanessa Coca, "New York City Goes to College: New Findings and Framework for Examining College Access and Success", Research Alliance for New York City Public Schools, NYU, 2017. https://research. steinhardt.nyu.edu/scmsAdmin/media/users/ks191/ New York City Goes to College Report.pdf

5 Alexandra A. Chaidez and Samuel W. Zwickel, "Makeup of the Class", Harvard University, 2018. https://features. thecrimson.com/2018/freshman-survey/makeupnarrative/. See chart "First-time Freshmen Enrollment by Race/Ethnicity and College: Percentages, Fall 2018", City University of New York, 2019. http://www.cuny.edu/ irdatabook/rpts2_AY current/ENRL 0017 RACE FTFR PCT.rpt.pdf

6 One illustrative example of current dynamics is that the share and number of first year students who are black entering Baruch College, the leading campus of the City University of New York [CUNY], is lower than at Harvard University. Lazar Treschan and Apurva Mehrotra, "UNINTENDED IMPACTS: Fewer Black and Latino Freshmen at CUNY Senior Colleges After the Recession", Community Service Society, 2012. Total undergraduate enrollment at Baruch, including transfer students, raises the share of black students to 11 percent.
7 Data for charts $1-3$ come from publicly available statistics offered on the NYCDOE website. All other charts in this report use data from HERE to HERE's own analysis of microdata from the 2013-2017 American Community Survey conducted by the United State Census Bureau.

8 "Improving Basic Programs Operated by Local Educational Agencies [Title I, Part A]", U.S. Department of Education, 2018. https://www2.ed.gov/programs/titleiparta/index. $\underline{\text { html }}$

9 Julia Freeland Fisher, "Not Just What but Who You Know Matters", 2018. https://www.educationnext.org/notjust-what-but-who-you-know-matters-freeland-fisherexcerpt/

10 Rebecca Unterman and Zeest Haider, "New York City's Small Schools of Choice: A First Look at Effects on Postsecondary Persistence and Labor Market Outcomes", MDRC, 2019. https://www.mdrc.org/sites/default/files/ SSC-First Look\%20Brief.pdf

11 Lazar Treschan and Apurva Mehrotra, "Challenging Traditional Expectations: How New York City's CTE High Schools Are Helping Students Graduate", Community Service Society, 2014. https://smhttp-ssl-58547. nexcesscdn.net/nycss/images/uploads/pubs/CSS CTE Print.pdf

12 Erin Jacobs Valentine, Chloe Anderson, Farhana Hossain, Rebecca Unterman, "An Introduction to the World of Work: A Study of the Implementation and Impacts of New York City's Summer Youth Employment Program", MDRC, 2017. https://www.dol.gov/sites/dolgov/files/OASP/legacy/ files/SYEP-Full-Report.pdf

13 James J. Kemple, “Career Academies: Long-term Impacts On Labor Market Outcomes, Educational Attainment, And Transitions To Adulthood", MDRC, 2008. https://www. mdrc.org/sites/default/files/full_50.pdf

14 John M.Nunley, Adam Pugh, Nicholas Romero, and R. Alan Seals, Jr., " College major, internship experience, and employment opportunities: Estimates from a résumé audit", Labour Economics, Volume 38, 2016. https:// www.sciencedirect.com/science/article/abs/pii/ $\underline{\text { S0927537115001207?via\%3Dihub }}$ 
15 Julia Freeland Fisher, "Not Just What but Who You Know Matters", 2018. https://www.educationnext.org/notjust-what-but-who-you-know-matters-freeland-fisherexcerpt

16 William C. Symonds, Robert Schwartz, and Ronald F. Ferguson, "Pathways to Prosperity: Meeting the challenge of preparing young Americans for the 21st century", Pathways to Prosperity Project, Harvard University Graduate School of Education, 2011. https:// www.gse.harvard.edu/sites/default/files/documents/ Pathways to Prosperity Feb2011-1.pdf

17 HERE to HERE analysis of data from the American Community Survey.

18 "Selected Economic Characteristics in New York City: 2017", 2017 American Community Survey, 2017. https:// data.census.gov/cedsci/table?d=ACS\%205-Year\%20 Estimates\%20Data\%20Profiles\&table=DP03\&tid=ACSDP5Y2017.DP03\&g=0400000US36 1600000US3651000\&I astDisplayedRow $=24$

19 "2005-2015 Graduation Rates Public - School", New York City Department of Education, 2019. https://infohub. nyced.org/reports-and-policies/citywide-informationand-data/graduation-results

20 Mark S. Granovetter, "The Strength of Weak Ties", American Journal of Sociology, Volume 78, Issue 6, 1973. https://sociology.stanford.edu/sites/g/files/ sbiybj9501/f/publications/the strength of weak ties and exch w-gans.pdf

21 J. Maureen Henderson, "When It Comes To Internships, Connections Matter Most", Forbes, 2017. https://www. forbes.com/sites/jmaureenhenderson/2017/06/30/ when-it-comes-to-internships-connections-mattermost/\#6b1947a22eed

22 HERE to HERE, with collaboration from Teens Take Charge, interviewed 17 high school students from different ends of the economic spectrum about the adults in their social network; whether they were able to access work-based learning opportunities; and the extent to which those opportunities came from the adults in their network or their schools.

23 Janie Boschmaronald And Brownstein, "The Concentration of Poverty in American Schools", The Atlantic, 2016. https://www.theatlantic.com/education/ archive/2016/02/concentration-poverty-americanschools/471414/
24 Darren Walker, "Internships Are Not a Privilege", The New York Times, 2016. https://www.nytimes. com/2016/07/05/opinion/breaking-a-cycle-thatallows-privilege-to-go-to-privileged.html

25 Katie Shepherd, "Part-Time Jobs and Thrift: How Unpaid Interns in D.C. Get By", The New York Times, 2016. https:// www.nytimes.com/2016/07/06/us/part-time-jobs-andthrift-how-unpaid-interns-in-dc-get-by.html

26 Caralee J. Adams, "'Soft Skills' Pushed as Part of College Readiness", EdWeek, 2012. https://www.edweek.org/ew/ articles/2012/11/14/12softskills_ep.h32.html

27 Drew C. Appleby, "The soft skills college students need to succeed now and in the future: Transferable skills for success in college and the workplace.", American Psychological Association, 2017. https://www.apa.org/ ed/precollege/psn/2017/09/soft-skills

28 Ron Young, "Soft Skills: The Primary Predictor of Success in Academics, Career and Life", Pairin, 2018. https://www. pairin.com/2018/07/13/soft-skills-primary-predictorsuccess-academics-career-life/

29 Tom Hilliard, "Degrees Of Difficulty: Boosting College Success In New York City", Center for an Urban Future, 2017. https://nycfuture.org/research/degrees-ofdifficulty

30 Tom Hilliard, "Degrees Of Difficulty: Boosting College Success In New York City", Center for an Urban Future, 2017. https://nycfuture.org/research/degrees-ofdifficulty

31 Staff from HERE to HERE conducted interviews, along with staff from the Hispanic Federation, with 12 young people who had recently left college without completing their degree, as well as seven recent college graduates. All interviews were conducted in May and June 2019.

32 Robert B. Schwartz and Amy Loyd, editors, "Career Pathways in Action: Case Studies From the Field." Harvard Education Press, 2019. Lazar Treschan, Abby Jo Sigal, Noel Parish, and Emily Roese, "Work is College Prep", HERE to HERE, 2018. https://static1.squarespace.com/ static/5a0b7e3cd74cff4595a4a87a/t/5ca1653c419202a 10bf41477/1554082101239/Work+is+College+Prep

33 https://www.shrm.org/ResourcesAndTools/hr-topics/ employee-relations/Pages/Employers-Say-StudentsArent-Learning-Soft-Skills-in-College.aspx 
34 Raj Chetty, "Higher Education and Upward Mobility: New Lessons from Big Data", Stanford University, 2018. https://www.gc.cuny.edu/CUNY GC/media/CUNYGraduate-Center/PDF/Event\%20Presentations/RChettyUpward-Mobility-Slides.pdf

35 Despite recent improvements, an overwhelming majority of CUNY community college students do not graduate, and just over half of BA candidates graduate: https://nycfuture.org/research/community-collegecompletion-in-new-york CUNY has recently gained the ability to access employment data for its students -its presentations about these data point to high, if not above average, rates of employment, but relatively low wages, even for BA graduates. https://capseecenter. org/wp-content/uploads/2014/09/3D-ChellmanCAPSEE-091914.pdf

36 Joiselle Cunningham, Abby Jo Sigal, Heather Johnson, and Julia di Bonaventura, "Employer Partnerships that Drive Systems Change," HERE to HERE and Jobs for the Future, October 2019

\section{7 https://static1.squarespace.com/} static/5a0b7e3cd74cff4595a4a87a/t/5ca16724f961 9a88d33570b0/1554082217864/The+CDOS+Pathway https://www.expandedschools.org/sites/default/files/ ES-Postsecondary-report-20190405.pdf
38 https://www.shrm.org/ResourcesAndTools/hr-topics/ employee-relations/Pages/Employers-Say-StudentsArent-Learning-Soft-Skills-in-College.aspx

39 http://www.ccnycampus.org/2018/12/special-reportthe-adjunct-crisis/ https://www.aaup.org/sites/ default/files/Faculty_Trends_0.pdf

40 See " An Agile University: Embracing the Future of Work and Improving the Quality of

41 See http://www.ptech.org/impact/results/ and http:// cte.nyc/site/content/benefits-cte-program-study.

42 For examples of quality apprenticeship programs, visit https://www.careerwisenewyork.org and https:// genesysworks.org/newyork/model-impact/ourimpact/.

43 Heather Johnson and Julia di Bonaventura, "Employer Partnerships that Drive Systems Change", Jobs for the Future and HERE to HERE, November 2019.

\section{4 https://nyachnyc.org/}

45 https://www.1199seiubenefits.org/funds-and-services/ training-and-employment/

46 https://www.heretohere.org/careerwise-new-york

\section{We believe that a significant expansion and enhancement of work-based learning represents the most promising way to provide opportunity to New York City high school and college students.}




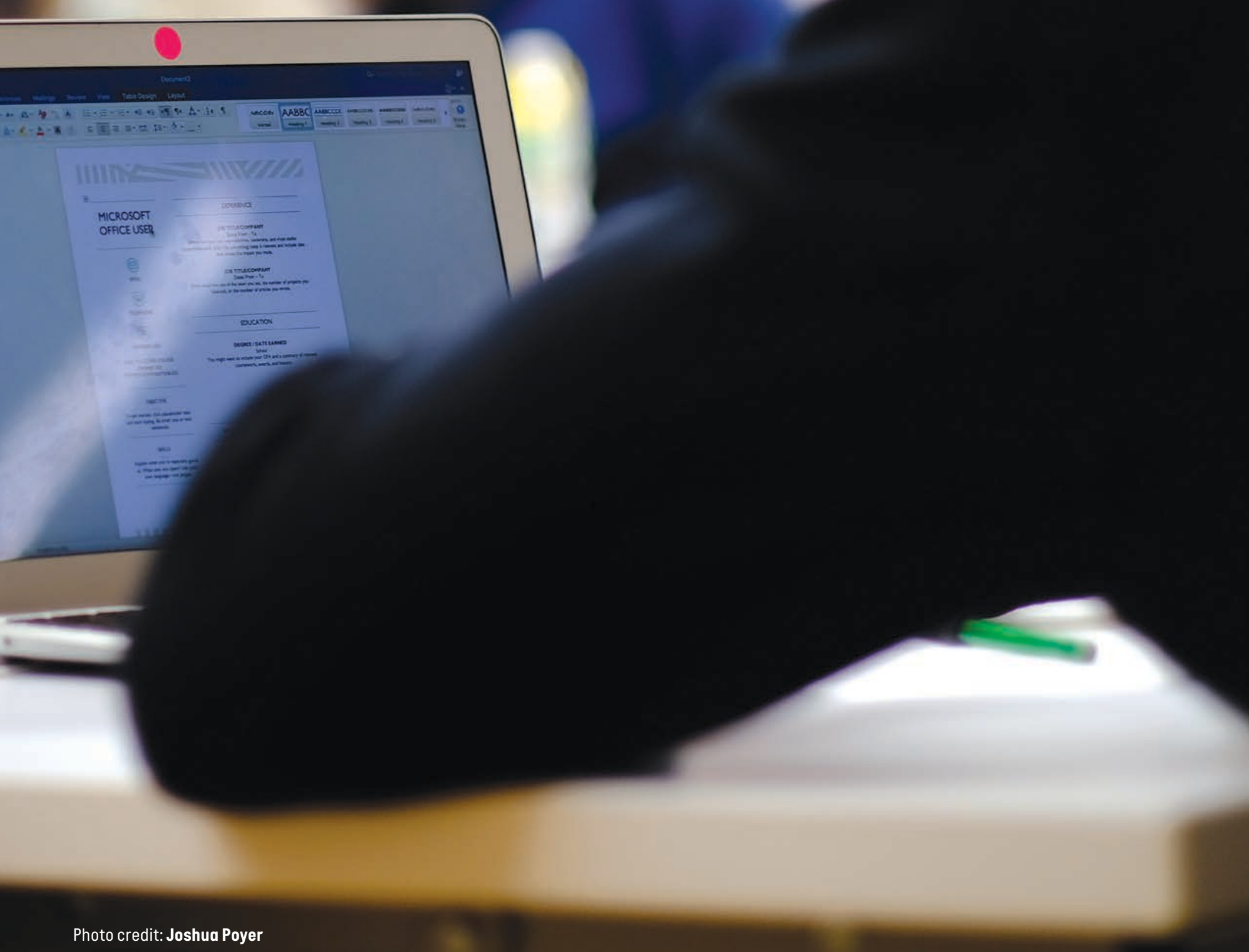


